\title{
Topography of Auditory Nerve Projections to the Cochlear Nucleus in Cats after Neonatal Deafness and Electrical Stimulation by a Cochlear Implant
}

\author{
Patricia A. Leake, Gary T. Hradek, Ben H. Bonham, and Russell L. Snyder \\ Epstein Laboratory, Department of Otolaryngology—Head and Neck Surgery, University of California San Francisco, 533 \\ Parnassus Avenue, Room \#U490, San Francisco, CA 94143-0526, USA
}

Received: 27 February 2008; Accepted: 30 April 2008; Online publication: 24 June 2008

\begin{abstract}
We previously reported that auditory nerve projections from the cochlear spiral ganglion (SG) to the cochlear nucleus $(\mathrm{CN})$ exhibit clear cochleotopic organization in adult cats deafened as neonates before hearing onset. However, the topographic specificity of these $\mathrm{CN}$ projections in deafened animals is proportionately broader than normal (less precise relative to the $\mathrm{CN}$ frequency gradient). This study examined SG-to-CN projections in adult cats that were deafened as neonates and received a unilateral cochlear implant at $\sim 7$ weeks of age. Following several months of electrical stimulation, SG projections from the stimulated cochleae were compared to projections from contralateral, non-implanted ears. The fundamental organization of SG projections into frequency band laminae was clearly evident, and discrete projections were always observed following double SG injections in deafened cochleae, despite severe auditory deprivation and/or broad electrical activation of the SG. However, when normalized for the smaller $\mathrm{CN}$ size after deafness, AVCN, PVCN, and DCN projections on the stimulated side were broader by $32 \%, 34 \%$, and $53 \%$, respectively, than projections in normal animals (although absolute projection widths were comparable to normal). Further, there was no significant difference between projections from stimulated and contralateral non-implanted cochleae. These findings suggest that early normal auditory experience may be essential for

Correspondence to: Patricia A. Leake · Epstein Laboratory, Department of Otolaryngology-Head and Neck Surgery - University of California San Francisco - 533 Parnassus Avenue, Room \#U490, San Francisco, CA 94143-0526, USA. Telephone: +1-415-4765958; fax: +1415-4762169; email: pleake@ohns.ucsf.edu
\end{abstract}

normal development and/or maintenance of the topographic precision of SG-to-CN projections. After early deafness, the $\mathrm{CN}$ is smaller than normal, the topographic distribution of these neural projections that underlie frequency resolution in the central auditory system is proportionately broader, and projections from adjacent SG sectors are more overlapping. Several months of stimulation by a cochlear implant (beginning at $\sim 7$ weeks of age) did not lessen or exacerbate these degenerative changes observed in adulthood. One clinical implication of these findings is that congenitally deaf cochlear implant recipients may have central auditory system alterations that limit their ability to achieve spectral selectivity equivalent to postlingually deafened subjects.

Keywords: auditory deprivation, cochlear spiral ganglion, cochlear prosthesis, congenital deafness, development, primary afferents, tonotopic organization, topographic maps

\section{INTRODUCTION}

In most sensory systems, the neighboring relationships of receptors within the sensory epithelium are maintained in their projections into the central nervous system. Such topographic maps comprise one of the fundamental organizing features of the central nervous system, and over the past few decades, there has been a major focus in developmental neurobiology on examining changes in the specificity of these maps during development and in defining the specific roles of afferent input and molecular cues in the formation 
and maintenance of precise topographic connections (see Rubel and Cramer 2002 for review). In the visual system, earlier studies of development emphasized that competition driven by activity is essential for refinement of initial broad or diffuse neuronal projections into more precise adult patterns (e.g., Guillery and Stelzner 1970; Shatz 1990; Goodman and Shatz 1993). Spontaneous waves of correlated rhythmic neural activity in retinal ganglion cells occur for some time before the onset of vision and are thought to be essential for the normal development of precise topographic maps at all levels of the visual system (Cang et al. 2005; Constantine-Paton et al. 1990; Maffei and Galli-Resta 1990; Shatz 1990, 1996; Goodman and Shatz 1993; Feller et al. 1996; McLaughlin et al. 2003b; O'Leary and McLaughlin 2005). Specific spatiotemporal patterns of spontaneous and visual input guide formation of precise synaptic connections (Zhou et al. 2003; Chiu and Weliky 2003), and progressive refinement of tectal receptive fields requires activity-dependent matching of the topography and strength of excitatory and inhibitory connections (Tao and Poo 2005).

In contrast, other studies have shown that the retinotectal projections are relatively precise from the time retinal fibers first reach the tectum (e.g., Chalupa and Snider 1998) and have emphasized the role of molecular cues in guiding the formation of precise projections (Cheng et al. 1995; Hansen et al. 2004; O'Leary and Wilkinson 1999; McLaughlin et al. 2003a; O'Leary et al. 1999; McLaughlin and O'Leary 2005; O'Leary and McLaughlin 2005). Thus, even for the retinotectal map, which is probably the beststudied of all topographic maps, the exact roles of and interactions between molecular mechanisms and neural activity in the formation and maintenance of spatially precise connections are still being debated.

The auditory nerve provides a particularly interesting model for examining molecular and activitydependent mechanisms underlying the formation of topographically precise projections. Like the visual system, the auditory system is very immature at birth in many mammals but precisely organized in adults. A basic feature of its organization is tonotopy, the orderly arrangement of best frequencies of the cochlear hair cells that is preserved within the spiral ganglion and in its projections to the cochlear nucleus. In the normal adult cat, auditory nerve fibers send collaterals to all three subdivisions of the cochlear nucleus $(\mathrm{CN})$, forming separate tonotopic maps and distinct synaptic connections in the anteroventral (AVCN), posteroventral (PVCN), and dorsal cochlear nuclei (DCN).

Functionally, newborn kittens are deaf due to the immaturity of the auditory system. By a few days postnatal $(\sim \mathrm{P} 3)$, the auditory nerve begins to exhibit spontaneous activity, but discharge rates and acoustic sensitivity remain very low until about P10-P14 (see
Walsh and Romand 1992 for review; Ehret and Romand 1981; Dolan et al. 1985). Previous studies of central auditory system development have reported a clear tonotopic gradient as soon as stimuli elicit a response (Ryan and Woolf 1988; Sanes et al. 1989; Webster and Martin 1991; Friauf 1992; Friauf and Kandler 1993). Our earlier anatomical studies examined the late gestational and perinatal development of projections from the cochlea to the $\mathrm{CN}$ by making focal injections of Neurobiotin ${ }^{\mathrm{TM}}(\mathrm{NB})$ into the spiral ganglion (SG) to study the $\mathrm{CN}$ projections from restricted sectors of the SG representing a narrow range of frequencies. These CN projections form discrete "frequency band laminae" within the AVCN, PVCN, small cell cap, and DCN, which exhibit clear cochleotopic organization in animals studied as young 5 days prenatal after caesarian section (Leake et al. 2002). However, quantitative analyses indicated that when normalized for $\mathrm{CN}$ size, the topographic restriction of projections in the perinatal group was less precise than in older kittens or adults. Projections to the AVCN were proportionately $>50 \%$ broader, and projections to both the PVCN and DCN were $>30 \%$ broader in neonates. Thus, significant refinement in the $\mathrm{CN}$ projections occurs during the first week postnatal (Leake et al. 2002), after which the projections are proportionate to those in adults (Snyder and Leake 1997).

In a recent study, recordings made directly from cochlear spiral ganglion cells in neonatal kittens during this pre-hearing period demonstrated distinctive bursting spontaneous discharge patterns (Jones et al. 2007). This activity is similar to the rhythmic spontaneous activity in retinal ganglion cells, shown to be essential in central refinement (O'Leary and McLaughlin 2005; Ruthazer and Cline 2004). Moreover, it occurs at precisely the time when the $\mathrm{CN}$ projections are becoming topographically restricted and thus may play a similar role. Soon after, immature bursting and rhythmic responses to high-intensity acoustic stimuli emerge in the auditory nerve (Fitzakerley et al. 1995, 1998) just before the emergence of adult-like frequency selectivity and sensitivity.

Our recent study examined the consequences of early profound hearing loss upon the SG-to-CN projections and showed that their precision is significantly reduced in animals that are deafened as neonates (Leake et al. 2006). The present study extends this work by examining the consequences of early profound hearing loss followed by unilateral electrical stimulation from a cochlear implant, upon the cochleotopic organization of the SG projections. Our hypothesis was that normal cochlear input (spontaneous and driven activity in the auditory nerve) is required for the full topographic refinement of the primary afferent inputs to the central auditory system. A corollary of this hypothesis is that when the 
selectivity of SG-to-CN projections is reduced due deafness occurring early in life, restoration of electrical activity in the auditory nerve via a cochlear implant may be effective in ameliorating or preventing these alterations. On the other hand, previous studies (Kitzes et al. 1995; Kitzes 1996; Moore and Kitzes 1985; Moore and Kowalchuk 1988) have reported that neonatal removal of one cochlea results in substantial reorganization of the central auditory projections, with projections from the intact $\mathrm{CN}$ more than doubling in size in their distribution to the auditory midbrain and forming highly ectopic projections to the brainstem superior olivary complex and medial nucleus of the trapezoid body. Thus, an alternative hypothesis is that electrical stimulation of one cochlea after neonatal deafening might exacerbate the reduced selectivity of $\mathrm{CN}$ projections and elicit substantially greater expansion or reorganization of auditory nerve projections in the $\mathrm{CN}$ ipsilateral to the implant. To evaluate these hypotheses, SG injections were made in adult cats that had been deafened by ototoxic drug administration beginning immediately after birth and subsequently stimulated unilaterally with a two-channel cochlear implant. Our objectives were to determine whether the normal topographic precision of the cochleotopic organization of the SG projections to the $\mathrm{CN}$ that underlies frequency selectivity in the normal auditory system can be restored and maintained into adulthood by application of a cochlear prosthesis after severe auditory deprivation early in life or alternatively if direct electrical stimulation of the auditory nerve would result in substantial reorganization of $\mathrm{CN}$ frequency band laminae in neonatally deafened animals.

\section{METHODS}

Neonatal deafening, cochlear implantation, and chronic electrical stimulation

All procedures involving animals in this study were approved by the Institutional Animal Care and Use Committee at the University of California, San Francisco and conformed to all NIH guidelines. Nine experimentally deafened animals were included in this study, and all were bred in a closed colony maintained at the University of California San Francisco. In addition, four normal adult cats were studied as controls.

As mentioned previously, kittens are unresponsive to sound over the first few days of life (Walsh and Romand 1992; Ehret and Romand 1981). The nine deafened animals included in this study received daily injections of the ototoxic aminoglycoside antibiotic, neomycin sulfate, $(60 \mathrm{mg} / \mathrm{kg} \mathrm{SQ}$ S.I.D.) beginning the day after birth and continuing for 18-24 days during the period when nearly adult-like hearing sensitivity normally de- velops. Profound hearing loss was confirmed by auditory brainstem response (ABR) testing as described previously (Leake et al. 1999, 2006). Briefly, at P17, animals were tranquilized with inhaled isoflurane (3\% via mask for induction; $1-2 \%$ for maintenance) and placed in a double-walled sound-attenuating chamber. A hollow tube was inserted into the external auditory meatus, and auditory stimuli were delivered through a headphone speaker (STAX-54) enclosed in a small chamber connected to the tube in the ear canal. The sound delivery system was calibrated with a sound level meter (Bruel and Kjaer 2209). Thresholds were determined for click-evoked auditory brainstem responses, averaging responses for at least 500 trials. If residual hearing was noted, it was always at significantly elevated thresholds compared to normal, and neomycin injections were continued in 2-3 day increments until no response was observed at the maximum intensity $(>105 \mathrm{~dB})$. Profound hearing losses induced by this method result in virtually total degeneration of hair cells throughout the cochlea (Leake et al. 1997). Table 1 presents the individual histories of these animals. The first group of four animals averaged 9 weeks of age (range, 8-11 weeks) and were studied to provide control data at the approximate age at which the second group of five deafened animals received unilateral cochlear implants. Stimulation histories for the older group also are shown. In addition, four of these implanted animals received daily injections of the selegiline (-)-desmethyldeprenyl (100 mg/kg SQ) concomitant with the administration of the ototoxic drug and continuing until the day of implantation in an effort to maintain better survival of the SG neurons because this drug has been shown to reduce neuronal apoptosis by a mechanism that is relevant to the SG neurons (Tatton et al. 1999). The data for the cochleae and $\mathrm{CN}$ projections on the non-implanted side of the older deafened group and adult control data have been reported previously (Leake et al. 2006).

A four-wire scala tympani electrode in a molded silicone rubber carrier was surgically implanted in the left cochlea as previously described (Leake et al. 1999, 2007), and electrical stimulation was initiated at about 7 weeks postnatal (range, 6-8 weeks). All animals received electrical stimulation with signals considered to be "temporally challenging" to the central auditory system (see Leake and Rebscher 2004; Vollmer et al. 1999). Stimulation periods were $4 \mathrm{~h} /$ day, 5 days/week for at least 6 months, except in one subject (K163) that was studied earlier due to device failure (Table 1). Concurrent stimulation was delivered on two bipolar channels: an apical pair of electrodes positioned about $11-12 \mathrm{~mm}$ from the base $(\sim 4-5 \mathrm{kHz})$ and a basal pair centered at $\sim 5-6 \mathrm{~mm}$ from the base $(\sim 12-$ $15 \mathrm{kHz}$ ). Electrodes comprising each pair were separated by $1 \mathrm{~mm}$. In four animals, the maximum electrical 
TABLE 1

Individual data on neomycin administration and age at study are shown for the groups of animals studied at 9 weeks and 8 months of age. In addition, for the older group that received a unilateral cochlear implant, the age at implantation, range of peak stimulus intensities applied, duration of stimulation periods, and stimulus frequency are shown. One subject (K154) received stimulation via an analogue speech processor (see text).

stimulation intensity was set at $2 \mathrm{~dB}$ above the electrically evoked auditory brainstem response (EABR) threshold using $200 \mu \mathrm{s} /$ phase biphasic pulses, as determined for each channel. EABR thresholds were determined regularly throughout stimulation periods and stimulators adjusted to maintain appropriate stimulation levels relative to EABR thresholds. Electrical stimuli were continuous trains of charge-balanced biphasic pulses delivered at 300 or 325 pps and $100 \%$ sinusoidally amplitude modulated at 30 and $60 \mathrm{~Hz}$. One subject (K154) received stimulation from ambient environmental sounds through a modified human analogue cochlear implant speech processor with stimulation set at a maximum stimulus amplitude of $6 \mathrm{~dB}$ above EABR threshold and processor outputs bandpass filtered at $850-1,450 \mathrm{~Hz}$ for the basal channel and at 250-850 Hz for the apical channel as described previously (Leake et al. 2000).

\section{Electrophysiological recording}

At the completion of chronic stimulation periods, animals were studied in acute electrophysiological experiments to record neural responses from the auditory midbrain or inferior colliculus (IC). Animals were first tranquilized with isoflurane. An intravenous catheter was inserted into the cephalic vein and a surgical level of anesthesia induced and maintained by infusion of sodium pentobarbital (20-40 mg/kg IV, to effect). Respiratory rate, heart rate, and body temperature were monitored throughout all procedures, and body temperature was maintained using a warm water recirculating blanket. The electrophysiological recording methods have been described in detail in several previous publications (Snyder et al. 1990, 2000; Leake et al. 2000; Leake and Rebscher 2004; Vollmer et al. 1999, 2005). Briefly, tungsten microelectrodes were used to record responses of multi-neuronal clusters and single neurons in several penetrations through the IC that were made along a standardized trajectory orthogonal to the tonotopic gradient of the IC. In each penetration, response thresholds to biphasic electrical pulses $(0.2 \mathrm{~ms}$ / phase) were determined at intervals of $100 \mu \mathrm{m}$ in response to electrical activation by each of the two bipolar cochlear implant channels used for chronic stimulation. To estimate thresholds, the intensities just sufficient to activate the neuron(s) were determined using audio-visual criteria. Thresholds were plotted as a function of depth along the tonotopic gradient of the IC to obtain spatial tuning curves (STC). STC widths were measured in each cat at the maximum electrical pulse intensity delivered to each stimulating channel during the chronic stimulation period immediately before the terminal, acute experiment. 


\section{Neurobiotin $^{\mathrm{TM}}$ injections}

After completion of the IC recording experiment, the auditory bulla was surgically exposed and opened, and the round window membrane was excised for direct visualization of Rosenthal's canal in the hook region and lower basal turn. In implanted cochleae, the mucosa and connective tissue over the Dacron cuff securing the electrode at the round window were dissected, and the electrode was carefully withdrawn. The fibrous and/or bony tissue encapsulating the electrode within the scala tympani was carefully dissected to access Rosenthal's canal. For each injection, a small opening through the bone of the modiolus overlying Rosenthal's canal was created using the tip of a 30-gauge needle as a curette.

The neuronal tracer Neurobiotin ${ }^{\mathrm{TM}}$ (from Vector Laboratories, Burlingame, CA, USA) was injected using thick-walled glass micropipettes with tips broken to a diameter of $\sim 10-30 \mu \mathrm{m}$. The micropipettes were filled with a solution of $5 \% \mathrm{NB}$ dissolved in distilled water. A small amount of the vital dye Trypan blue $(<0.5 \%)$ was added to the NB solution so that injections could be confirmed visually. The micropipette was mounted on a 1- $\mu$ l microsyringe (Unimetrics) or attached to a Picospritzer II $^{\mathrm{TM}}$ (General Valve) picoliter injector, positioned over the opening in Rosenthal's canal and inserted into the SG using a micromanipulator. A small amount of $\mathrm{NB}(\sim 0.5 \mu \mathrm{l})$ was injected either manually or with the Picospritzer II ${ }^{\mathrm{TM}}$. The tip of the pipette was left in place for about $10 \mathrm{~min}$ to allow the tracer to diffuse into the ganglion. In most animals, injections were made at two locations in each cochlea. The locations of injections were recorded, and the round window was sealed with a small disk of plastic wrap (Saran ${ }^{\mathrm{TM}}$ wrap, Dow Corning). The incisions were sutured closed, and animals were maintained lightly anesthetized for postinjection periods of $7-12 \mathrm{~h}$ to allow sufficient time for the tracer to be transported to the $\mathrm{CN}$ and to completely fill the central axons of the SG neurons.

Table 2 presents data for individual subjects in the first experimental group of four neonatally deafened animals studied at 9 weeks of age and in the second experimental group of five neonatally deafened animals that received a cochlear implant and intracochlear electrical stimulation. The table indicates the number of successful SG Neurobiotin ${ }^{\mathrm{TM}}$ injections made in each cochlea, the mean SG density (averaged for the entire cochlea), and $\mathrm{CN}$ volumes. Control data were obtained from four normal adult cats (eight $\mathrm{CN}$ from two male and two female cats). Note that some of the data for the normal cats and non-stimulated cochleae and CN of the older deafened group were presented previously (Leake et al. 2006). However, in the prior study, CN size was estimated from cross-sectional areas of representative sections, whereas in this study, we report $\mathrm{CN}$ volumes and projection data are normalized to crosssectional areas throughout the $\mathrm{CN}$.

\section{Preparation of cochlear specimens}

Fixation, NB cytochemistry, embedding, and sectioning for light microscopy

After the post-injection period, the cochleae were preserved by infusion of mixed aldehyde fixative

TABLE 2

\begin{tabular}{|c|c|c|c|c|}
\hline \multicolumn{5}{|c|}{ Individual subject data } \\
\hline Cat number & Age at study (weeks) & $\begin{array}{c}\text { Number of SG injections: } \\
\text { left, right }\end{array}$ & $\begin{array}{l}\text { SG density (area fraction, } \\
\text { percent of normal): left, right }\end{array}$ & $\begin{array}{c}\mathrm{CN} \text { volume }\left(\mathrm{mm}^{3}\right): \\
\text { left, right }\end{array}$ \\
\hline \multicolumn{5}{|c|}{ Neonatally deafened group studied at $\sim 9$ weeks of age } \\
\hline 118 & 8 & 1,1 & - & $9.04,-$ \\
\hline 119 & 8 & 2,1 & - & $9.02,9.39$ \\
\hline 666 & 10 & 2,2 & - & $10.31,10.15$ \\
\hline 711 & 11 &,- 1 & - &,- 10.19 \\
\hline \multicolumn{5}{|c|}{ Neonatally deafened group after unilateral electrical stimulation (left cochlea) } \\
\hline K154 & 34 & 1,1 & $35.7,40.1$ & $14.70,16.14$ \\
\hline K158 & 41 & 2,2 & $55.9,37.1$ & $13.81,14.13$ \\
\hline K160 & 34 & 1,2 & $21.7,37.3$ & $12.46,13.81$ \\
\hline K163 & 20 & 2,2 & $91.5,84.2$ & $14.80,15.85$ \\
\hline K169 & 33 &,- 2 & $28.2,23.7$ & $16.14,14.10$ \\
\hline \multicolumn{5}{|c|}{ Normal adult controls } \\
\hline 423 & 124 & 3,3 & - & $22.00,21.18$ \\
\hline 596 & 157 & 2,2 & - & $22.58,20.98$ \\
\hline 654 & 37 & 2,2 & - & $20.74,23.38$ \\
\hline 944 & NA & 1,1 & - & $20.05,18.45$ \\
\hline
\end{tabular}

Age at study, number of successful SG injections made in each cochlea, and CN volume are presented for individual subjects in the groups of deafened animals studied at 9 weeks and 8 months of age and for normal adult controls. In addition, individual SG density data are shown for the implanted group. 
(2.5\% paraformaldehyde and $1.5 \%$ glutaraldehyde in $0.1 \mathrm{M}$ phosphate buffer at $\mathrm{pH}$ 7.4) directly into the scalae through the round and oval windows. A lethal dose of sodium pentobarbital was administered, and transcardiac perfusion was carried out $(5 \%$ lactated Ringer's solution followed by fixative: $0.5 \%$ paraformaldehyde, $2.5 \%$ glutaraldehyde, and $4 \%$ sucrose in $0.1 \mathrm{M}$ phosphate buffer at $\mathrm{pH}$ 7.4). The brain and temporal bones were removed for histology.

The cochlea was dissected (thinning the otic capsule bone with a diamond dental burr) and post-fixed for $12 \mathrm{~h}$ in $1 \%$ phosphate-buffered osmium tetroxide with $1.5 \%$ potassium ferricyanide. Specimens then were partially decalcified in $0.1 \mathrm{M}$ EDTA for $18 \mathrm{~h}$, dehydrated, and embedded in LX ${ }^{\mathrm{TM}}$ epoxy resin. Extra-thick surface preparations were made as previously described (Leake et al. 2006). Half-coils of the cochlea containing the organ of Corti and adjacent SG were removed using razor blades and mounted in LX on glass slides (or cut into smaller pieces as necessary to orient the basilar membrane parallel to the slide). The basilar membrane was measured from base to apex along the pillar cells, and blocks containing $\sim 0.5 \mathrm{~mm}$ of the organ of Corti and associated SG were removed at $\sim 2-\mathrm{mm}$ intervals throughout the cochlea. The samples were remounted in the radial plane, and semi-thin sections $(1-2 \mu \mathrm{m})$ were cut and stained with toluidine blue. Additional blocks were prepared and serial sections cut in the regions where the NB injection sites were identified, and serial sections were cut to define the limits of each injection site.

\section{Analysis of injection sites}

Sections through cochlear injection sites were examined in the light microscope (Zeiss, Axioskop 2), and high-resolution video images $(2,584 \times 1,936$ pixels $)$ for illustrations were acquired using Photoshop 5.0, a Kodak digital camera, and a PC. For calibration, an image of a micrometer scale was captured and superimposed on each image.

In our previous studies of the SG-to-CN projections in normal cats, the extent of each NB injection site was defined by the distribution of labeled afferent fibers and terminals innervating inner hair cells (e.g., Leake et al. 2002). This method cannot be used in deafened animals because the cochlear hair cells and many of the radial nerve fibers have degenerated. Previous studies also showed that due to the relative impermeability of the bone, penetration of cytochemical reagents was inadequate to demonstrate NB reaction product in the Rosenthal's canal. Therefore, the location and extent of injections were defined by examining serial sections through each injection site for evidence of penetration of the pipette into Rosenthal's canal and to locate damaged, pyknotic, and missing SG cell somata. The injection site locations were defined first by absolute distance in millimeter from the basal end of the organ of Corti. Next, total basilar membrane length in each cochlea was used to calculate the positions of injection sites as percent distance from base. This allowed us to calculate the represented frequencies encompassed by each injection (and resulting CN projections) using Greenwood's frequencyposition function (Greenwood 1974, 1990) with the revised constants provided by Liberman (1982) for the cat cochlea.

\section{Spiral ganglion cell density}

Morphometric analysis of the SG cell somata in Rosenthal's canal was performed to quantify neuronal survival as a function of cochlear location, using a point counting method as described previously (Leake et al. 1999; Leake et al. 2007). Briefly, at each selected location, five sections cut at intervals of $>50 \mu \mathrm{m}$ were examined at $\times 400$ in the light microscope. A counting grid $\left(10 \mathrm{~mm} \times 10 \mathrm{~mm}\right.$; field area $=90,000 \mu \mathrm{m}^{2}$ at $\left.\times 400\right)$ was placed in the microscope ocular and the section positioned with the grid over Rosenthal's canal. The area fraction of the SG cells was determined by counting the number of grid line intersections that fell over cell somata and dividing by the number of intersections over Rosenthal's canal. This value represents the ratio of Rosenthal's canal area occupied by the SG cells. Previous studies provided normative data for the cat SG (Leake et al. 1999), allowing data to be expressed as percent of normal. Area fraction data were pooled into $10 \%$ sectors from base to apex based upon the total basilar membrane length as determined in each surface preparation. Note that the data for the non-stimulated cochleae were reported previously (Leake et al. 2006, Fig. 2B). For overall group comparisons to assess the effects of electrical stimulation on SG cell density, the mean area fraction for each cochlear sector was calculated, and data for paired cochlear sectors were compared using a twoway ANOVA pair-wise multiple comparisons procedure (Tukey test). All statistical analyses were performed using Sigma Stat (version 2.03) software.

\section{Preparation of cochlear nucleus sections and analysis of NB-labeled projections}

\section{Preparation of $C N$ sections and NB cytochemistry}

Following the transcardiac perfusion, the brainstem was isolated (rostral midbrain to caudal medulla), rinsed in Ringer's solution, and placed in $40 \%$ sucrose in $0.1 \mathrm{M}$ phosphate buffer at $\mathrm{pH} 7.4$ at $4^{\circ} \mathrm{C}$ until saturated. The brain was marked on the right side, frozen rapidly with dry ice, and serial coronal sections were cut at $50 \mu \mathrm{m}$. Sections were rinsed in $0.05 \mathrm{M}$ TRIS 
(pH 7.6) and phosphate buffer, incubated in VECTASTAIN ${ }^{\mathrm{TM}}$ ABC reagent solution from Vector Laboratories for $12 \mathrm{~h}$ at $4^{\circ} \mathrm{C}$ and rinsed in $0.05 \mathrm{M}$ TRIS buffer. The NB/ABC complex was visualized using 3,3'diaminobenzidine tetrahydrochloride (DAB; Sigma) substrate with cobalt intensification as described previously (Leake et al. 2006). Sections were pre-incubated for $30 \mathrm{~min}$ in $100 \mathrm{ml}$ TRIS buffer containing $20 \mathrm{mg}$ of $\mathrm{DAB}, 1 \mathrm{mg}$ cobalt chloride, and $1 \mathrm{mg}$ nickel ammonium sulfate, transferred to fresh DAB with one drop of $3 \%$ hydrogen peroxide, and incubated for an additional 60-120 min until emerging background staining was evident in sections examined under the microscope. The sections were rinsed, mounted on gelatinized slides, dehydrated, cleared, and coverslipped in Permount ${ }^{\mathrm{TM}}$. Tissue shrinkage was evaluated previously by direct measurements made in wet sections and repeated in the same sections after drying, clearing, and mounting. Mean shrinkage was less than $0.5 \%$ in brainstem sections processed in this manner (Leake et al. 2002).

\section{CN cross-sectional area measurements, volume calculations,} and scaling factors

To evaluate the reduced size of the $\mathrm{CN}$ in deafened animals, measurements were made in sections selected at $10 \%$ intervals. Sections were imaged digitally and measured at a resolution of about $6.5 \mu \mathrm{m} /$ pixel $(640 \times$ $480=4.18 \mathrm{~mm} \times 3.13 \mathrm{~mm}$ ) in Image J software (Rasband 2006; version $1.34 \mathrm{~N}$ ). The perimeter of the $\mathrm{CN}$ was outlined using the tracing tool and the area calculated using the area function. The $\mathrm{CN}$ volume was calculated by multiplying the ten cross-sectional area values by the total number of sections and by section thickness $(50 \mu \mathrm{m})$. The values for $\mathrm{CN}$ volume were compared among groups using an unpaired Student's $t$ test (Bonferroni correction).

For normalizing the measurements of labeled auditory nerve projections relative to the smaller size of the $\mathrm{CN}$ in deafened animals, we calculated the square root of the mean of the cross-sectional areas from the $20-80 \%$ intervals of the $\mathrm{CN}$ (region where the main development of the labeled projections was seen) in each subject to provide an estimate of relative size in a single dimension (re: CN projection thickness). These values were used to calculate a scaling factor: The square root of the mean of these $\mathrm{CN}$ areas was calculated for each deafened subject and divided by the mean of the values for the normal adult group.

\section{Measurements of CN projection laminae}

The nomenclature used here for the cytoarchitectonic subdivisions and cell types of the cochlear nucleus follows that of Osen $(1969,1970)$ because smaller subdivisions defined in Golgi material (Brawer et al.
1974; Cant and Morest 1984; Tolbert and Morest 1982) are difficult to distinguish in our unstained sections reacted for demonstration of NB labeling. For descriptions of labeled fiber and synaptic terminal morphology, the terminology of Rouiller et al. (1986) is adopted. For quantitative analysis of projections, digital images were captured at a resolution of approximately $1 \mu \mathrm{m} /$ pixel $(640 \times 480$ pixels $=0.640 \mathrm{~mm} \times$ $0.480 \mathrm{~mm}$ ). The thickness of each lamina of labeled axons and terminals was measured using the "profile scan" analysis function of the public domain NIH Image program (developed at the U.S. National Institutes of Health; on the Internet at http://rsb.info. nih.gov/nih-image/) software, version 1.63 , as described previously (Leake et al. 2006). Measurements were made in serial sections through the main development of each projection in each $\mathrm{CN}$ subdivision. Sections at the rostral and caudal extremes of laminae were excluded to avoid tangential measurements. Projection thickness was measured orthogonal to the plane of the individual $\mathrm{CN}$ projection lamina in order to estimate the distribution of labeled fibers across the frequency gradient within each subdivision. AVCN and PVCN laminae were measured in a roughly dorsal-toventral axis orthogonal to their long axes, and the DCN projections were measured in an axis parallel to the pial surface. Scans were executed beginning at the low frequency side of the laminae (ventral to dorsal) using a $0.05-\mathrm{mm}$ by $0.4-0.8-\mathrm{mm}$ window. Three scans were made in each selected image ( $\sim 90$ scans in each $\mathrm{CN})$. All scans for a given projection were averaged, and mean pixel density was displayed as a function of distance across the window. The threshold was set to a level at which some negative values occurred on both sides of the pixel-density peak within the window. The point at which the first negative number appeared was determined on each side of the peak, and the total pixel value for all bins between the two points was assigned a value of $100 \%$. The distance containing $90 \%$ of the total pixel-density was calculated and defined as the projection thickness. The Student's $t$ test (unpaired) was used for comparisons of projections in deafened and control subjects, except when the data failed the $t$ test assumption of normality (equal variance) in which case the Mann-Whitney rank sum test was used. The same tests were used to compare projection thickness in deafened subjects with "predicted" values (the values predicted if projections in the smaller $\mathrm{CN}$ of deafened subjects were proportionate to those in normal controls). Predicted values were calculated by multiplying the average projection thickness measured in each CN subdivision in controls by the scaling factor (as described above).

Digital images for photomicrograph illustrations were captured as tiff files (resolution of 2,584 $\times 1,936$ pixels) using Axiovision AC software (v. 4.2.0.0). Images 
were imported into Photoshop (v. 8) or Canvas (v.9) to add labels and scale bars. In some images, background subtraction was used, and contrast and brightness were adjusted to match the images appearing within the same figure.

\section{RESULTS}

Efficacy of chronic electrical stimulation by the cochlear implant

Electrical stimulation was delivered by the cochlear implant for periods of 25-34 weeks in four of the implanted animals. Acute recording experiments were conducted in these subjects to evaluate the efficacy of the electrical stimulation delivered by the implant over the previous months and to characterize the extent of activation elicited by the electrical stimuli within the central auditory system. Subject K163 damaged its implant and was studied after only 14 weeks of stimulation. In this animal, we were able to bypass the broken wires and reconnect to the intracochlear electrodes near the auditory bulla to conduct an electrophysiology experiment. However, EABR thresholds were found to be higher than before the wire breakage, and, therefore, the electrophysiology data collected in this animal were excluded from the present analysis.

Neural response thresholds were plotted as a function of depth along the cochleotopic gradient of the IC to obtain STC functions, as reported previously (Snyder et al. 1990, 1991; Vollmer et al. 1999; Leake et al. 2000, 2007; Leake and Rebscher 2004). In the present study, extent of activation of the IC was measured at the maximum electrical signal intensities of the amplitude modulated pulse trains (or analogue signal in K154) used for the electrical stimulation delivered to each implant channel in that particular subject. In previous studies, measured STCs for sinusoidal stimuli were typically W-shaped, and the highest threshold site between the two minimum thresholds was defined as the border between the external nucleus (ICX) and central nucleus of the IC (ICC). In the present study, STCs for pulse stimuli often did not exhibit the typical W-shaped functions and consequently did not allow for reliable distinction between the ICX and the ICC. However, these STC data do provide an estimate of the extent of excitation across the tonotopic gradient of the IC (spatial selectivity or tuning) for each channel of the implant. Table 3 presents the mean IC activation widths (average of all IC penetrations) in each subject, for the apical channel bipolar electrode pair 1, 2 and for the basal channel 3, 4. Values are expressed as percentage of the total IC depth over which responses were recorded.

The areas activated by the two channels were summed (subtracting any overlapping area), and this value was divided by the total IC depth over which responses were recorded at in the same penetration. This value (means shown in third column) provides an estimate of the percentage of the entire IC cochleotopic (frequency) gradient activated at maximum stimulus intensity. The total activation areas were very broad, ranging from $91 \%$ to $96 \%$. Thus, the amplitude modulated electrical signals applied for chronic stimulation in these animals (100\% modulation depth) varied in intensity from below threshold to levels that activated quite broadly across the frequency range of the auditory midbrain (and presumably also broadly across the $\mathrm{CN}$ ).

Table 3 also compares the minimum IC thresholds with the final stimulation intensities for each channel

TABLE 3

Spatial extent of IC activation elicited by chronic stimulation

\begin{tabular}{|c|c|c|c|c|c|c|c|c|c|}
\hline \multirow[b]{2}{*}{ Cat number } & \multicolumn{3}{|c|}{$\begin{array}{l}\text { IC activation at maximum } \\
\text { stimulus intensity } \\
\text { (mean percent of total) }\end{array}$} & \multicolumn{2}{|c|}{$\begin{array}{c}\text { Minimum IC threshold } \\
\text { pulses }(0 d B=1 \mu \mathrm{A})\end{array}$} & \multicolumn{2}{|c|}{$\begin{array}{l}\text { Final stimulus intensity } \\
\qquad(0 d B=1 \mu A)\end{array}$} & \multicolumn{2}{|c|}{ Difference $(d B)$} \\
\hline & 1,2 & 3,4 & $1,2+3,4$ & 1,2 & 3,4 & 1,2 & 3,4 & 1,2 & 3,4 \\
\hline K154 & 91 & 26 & 91 & 43 & 56 & 55 & 57 & 12 & 1 \\
\hline K158 & 88 & 88 & 93 & 40 & 46 & 48 & 50 & 8 & 4 \\
\hline K160 & 82 & 89 & 96 & 42 & 40 & 52 & 47 & 10 & 7 \\
\hline K169 & 86 & 90 & 93 & 38 & 38 & 52 & 48 & 14 & 10 \\
\hline Average & 87 & 73 & 93 & 41 & 45 & 52 & 51 & 11 & 6 \\
\hline SD & 4 & 32 & 2 & 2 & 8 & 3 & 5 & 3 & 4 \\
\hline
\end{tabular}

Summary of electrophysiological data for 4 of the individual subjects that received a cochlear implant and several months of electrical stimulation. The average spatial extent of activation area measured across the cochleotopic gradient in the inferior colliculus is estimated for the apical stimulation channel (electrodes 1,2 ), for the basal channel (electrodes 3,4), and for combined stimulation of both channels at the peak intensities of the modulated signals used for the final period of electrical stimulation in each cat immediately before study. For the animal stimulated with the speech processor (K154), the final stimulus levels have been adjusted to estimate equivalent charge for the sinusoidal stimulus waveforms of longer average phase durations. Levels for chronic stimulation were set $2 \mathrm{~dB}$ above EABR threshold (or $6 \mathrm{~dB}$ for the speech processor), and minimum IC thresholds were consistently lower than the final peak stimulation levels. (Differences shown in last 2 columns) 
in each subject. Chronic stimulation levels were set at $2 \mathrm{~dB}$ above the EABR threshold ( $6 \mathrm{~dB}$ for $\mathrm{SP}$ ), but note that IC thresholds were consistently, and often substantially, lower than the chronic stimulation levels, indicating that neural thresholds in the IC are systematically lower than the evoked response thresholds as reported previously (Beitel et al. 2000).

\section{Spiral ganglion cell degeneration}

In the experimental group studied at about 8 months of age after several months of electrical stimulation from a cochlear implant, examination of histological sections showed that all the cochlear hair cells had degenerated in both stimulated (left) and control deafened cochleae. Further, many (or most) of the peripheral radial nerve fibers within the osseous spiral lamina (the dendrites of the SG neurons) also had degenerated, and significant cell loss within the SG itself was observed due to the relatively long durations of deafness. The average SG area fraction (an unbiased stereological measure of the relative area of Rosenthal's canal occupied by SG cells) was about $46 \%$ of normal for the left (stimulated) and $43 \%$ of normal for the right (non-stimulated) cochleae (Fig. 1). Four of the five deafened/implanted animals received 68 weeks of selegiline administration in an effort to reduce the degenerative effects of deafness. However, the degeneration of the spiral ganglion observed in

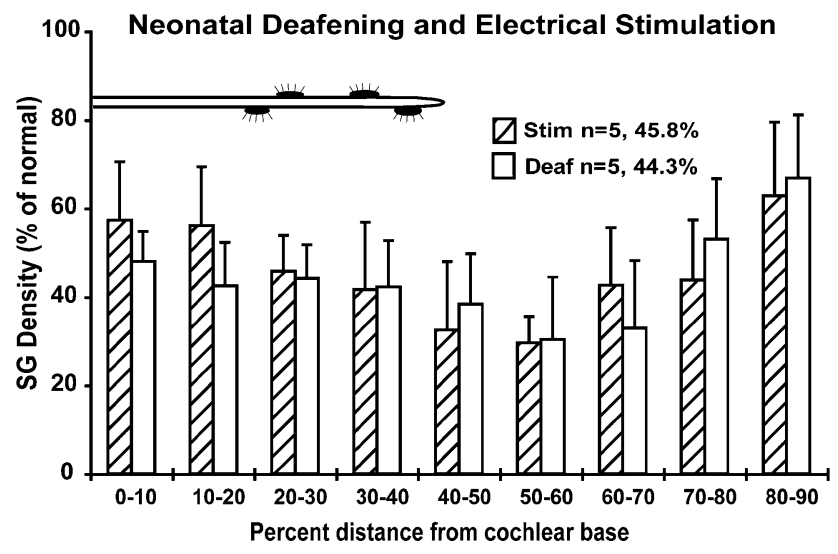

FIG. 1. Spiral ganglion cell density data, as assessed by measuring area fraction, are shown for neonatally deafened cats that received a unilateral cochlear implant at about 7 weeks postnatal and several months of electrical stimulation of the left cochlea. Data are expressed in percent of normal for $10 \%$ sectors of the cochlea from base to apex. Averaged overall SG density was about $46 \%$ of normal in the stimulated cochleae and $44 \%$ in the contralateral nonstimulated ears. The diagram at the top of the graph shows the approximate position of the stimulating contacts of the cochlear implant relative to the sectors of the spiral ganglion. The data for the non-stimulated cochleae were published previously (from Leake et al. 2006, Fig. 2B) and are shown here for direct comparison with the stimulated ears with permission from Journal of Comparative Neurology, Wiley. Bars indicate standard error of the mean. these animals is similar to results seen previously in neonatally deafened subjects with no selegiline treatment (Leake et al. 2006, 2007). Further, the single cat that did not receive selegiline (K154) had SG densities and $\mathrm{CN}$ volumes (Table 2) that fell in the middle of ranges observed in the four other subjects, indicating that the selegiline actually had little or no effect. Note that the area fraction data reflect both cell loss and reduction in cell size from normal. Although we did not evaluate cell areas here, our previous studies have demonstrated significant reductions in SG cell size in these neonatally deafened cats, with cross-sectional soma areas measuring about $75 \%$ of normal after comparable durations of deafness (Leake et al. 1999, 2007). Thus, SG area fraction data likely underestimate the actual number (percentage of normal) surviving SG neurons and should be considered minimum estimates. One animal (K160) showed histopathological evidence of infection that affected the SG survival in the left cochlea, which exhibited the lowest survival of all of the studied cochleae (overall area fraction, $21.7 \%$ of normal).

\section{Analysis of $\mathrm{NB}^{\mathrm{TM}}$ injection sites}

Because no intact hair cells were present in these deafened animals, we emphasize that the "represented frequencies" of injections were calculated based upon cochlear location in deafened animals only for the purpose of comparing the sites and sizes of injections to the normal control group. These values are not meant to imply that the organ of Corti was functional in the deafened animals. Further, because frequency calculations are based upon percentage of basilar membrane length, it is important to note that the mean basilar membrane length in the deafened group (24.6 mm, $n=$ 10) was identical to the mean for normal adult cats $(24.6 \mathrm{~mm})$. This finding is consistent with our previous study, demonstrating that the basilar membrane length in kittens studied at 0 to 3 days postnatal is not significantly different from that of adult cats (Leake et al. 2002). The basilar membrane was already full adult length at the time we began ototoxic drug injections, and, therefore, its length was normal in the deafened animals.

The extent of each injection site was evaluated in serial sections examined for evidence of the penetration of the NB pipette into Rosenthal's canal and degenerating or missing SG cells (Fig. 2). Because injections were made through the round window, injection sites were limited to relatively high-frequency basal locations ranging from $\sim 1.5$ to $6.5 \mathrm{~mm}$ from the base, equivalent to a frequency range of approximately 45 to $15 \mathrm{kHz}$ in the normal adult cat cochlea (Greenwood 1974; Liberman 1982). Whenever possible, two injections were made in each cochlea at sites that were separated as widely as possible in the 


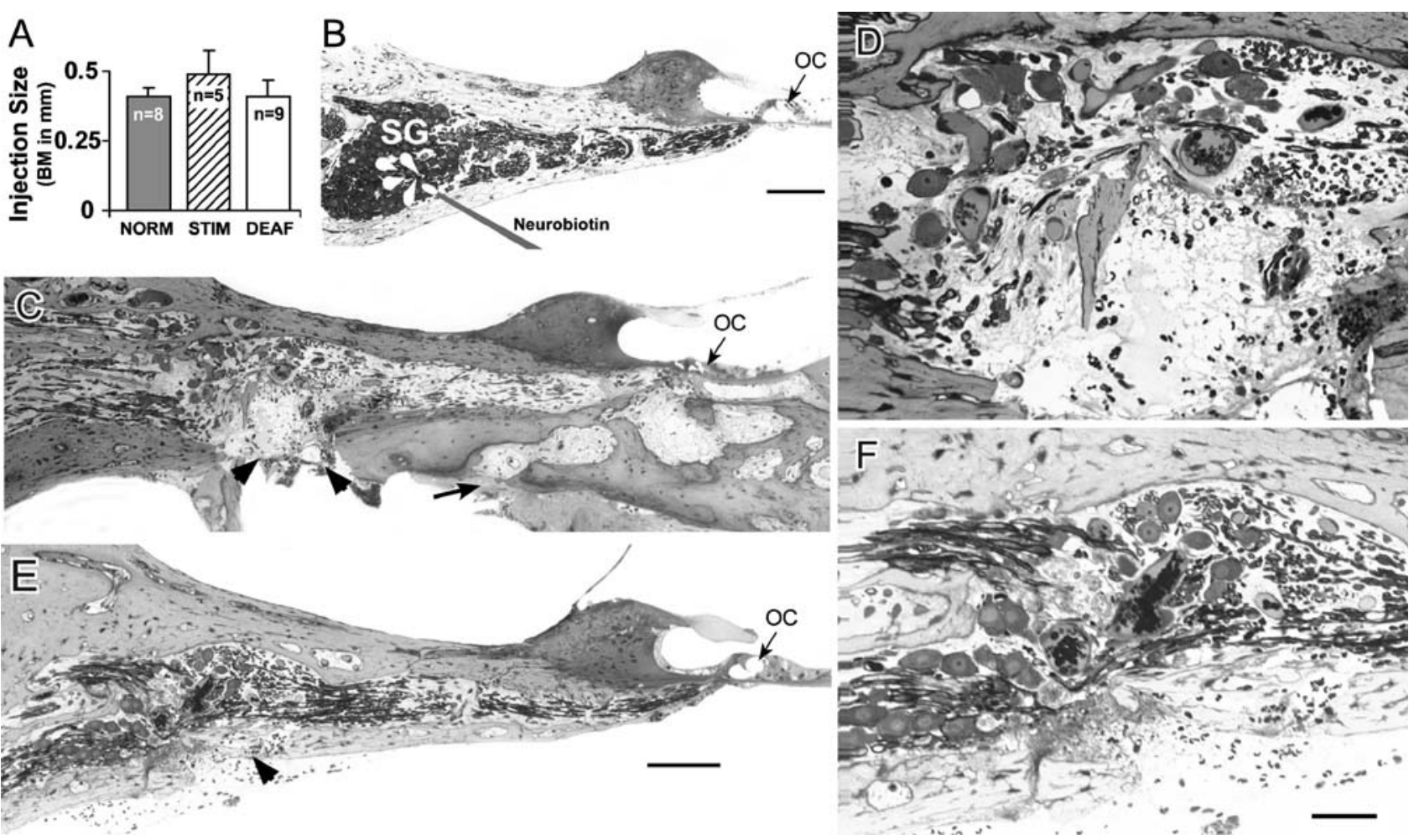

FIG. 2. A Injection site size in the normal adult controls averaged $412 \mu \mathrm{m}$, and this value was not significantly different from the average size of injections in the stimulated $(490 \mu \mathrm{m})$ and deafened cochleae $(407 \mu \mathrm{m})$ of the implanted animals. B Image of a radial section through the organ of Corti $(O C)$ and SG illustrating the method for making NB injections directly into the ganglion. C Low magnification image showing an injection site in a cat deafened neonatally and examined after implantation and 28 weeks of electrical stimulation (K154). This section from the implanted cochlea at about $6 \mathrm{~mm}$ from the base $(\sim 16.7 \mathrm{kHz}$ in a normal cochlea) illustrates the area of maximum damage from the injection. Arrowheads indicate the defect created in the modiolar bone through which the glass micropipette was inserted to make the injection. Most of the radial nerve fibers have degenerated

accessible cochlear region. The more apical injections were made at about where the basal stimulation channel (electrodes 3,4) of the cochlear implant was centered, at 5-6 $\mathrm{mm}$ from the base. Due to the fibrotic and sometimes bony encapsulation of the cochlear implant (Fig. 2C), it was more difficult to make injections in implanted cochleae, and only six successful NB injections were made in the implanted ears (left side), compared to nine injections in the contralateral cochleae. These restricted injections labeled small groups of SG neurons that normally would innervate cochlear sectors ranging in length from $\sim 300$ to $500 \mu \mathrm{m}$. The injections in the stimulated cochleae (five of six injection sites measured) and in the deafened control cochleae (nine of nine injection sites measured) averaged 490 and $407 \mu \mathrm{m}$, respectively, and these values were not significantly different from the average injection size in normal within the osseous spiral lamina due to the duration of deafness, and the bone encapsulating the implant in the scala tympani is seen at the right (arrow). D Higher magnification of Rosenthal's canal in the same section. Only a few ganglion cells are recognizable. E Section through Rosenthal's canal taken about $5.4 \mathrm{~mm}$ from the base $(\sim 21 \mathrm{kHz})$ showing the site of the more apical injection in the deafened, non-implanted cochlea of another animal (K160). The arrow indicates the defect in the modiolar bone through which the micropipette was inserted. A small hemorrhage is apparent. F Higher magnification of Rosenthal's canal in the section shown in E. A few SG cells are recognizable, but most have degenerated. Scale bar in $\mathbf{E}=100 \mu \mathrm{m}$ and also indicates magnification for $\mathbf{B}, \mathbf{C}$, and $\mathbf{E}$. Scale bar in $\mathbf{F}=25 \mu \mathrm{m}$ and also indicates magnification for $\mathbf{D}$.

controls $(412 \mu \mathrm{m})$. In a normal adult cat, there are about 100 inner hair cells per millimeter of basilar membrane distance (Liberman 1982), and $1 \mathrm{~mm}$ of basilar membrane is innervated by a sector of the spiral ganglion approximately $0.6 \mathrm{~mm}$ in length in the basal cochlea (Keithley and Cronin-Schreiber 1987).

\section{Measurements of $\mathrm{CN}$ cross-sectional area and volume calculations}

The overall size of each $\mathrm{CN}$ was determined in coronal sections selected at $10 \%$ intervals by tracing the perimeter of the $\mathrm{CN}$ complex in digitized images as illustrated in Figure 3A-D. The cross-sectional areas were calculated with NIH Image and used to estimate CN volume (see "Methods"). In normal adult controls, CN volume ranged from 18.5 to $23.6 \mathrm{~mm}^{3}$, with a mean of $21.2 \mathrm{~mm}^{3}$ (Table 2). In the deafened/ 


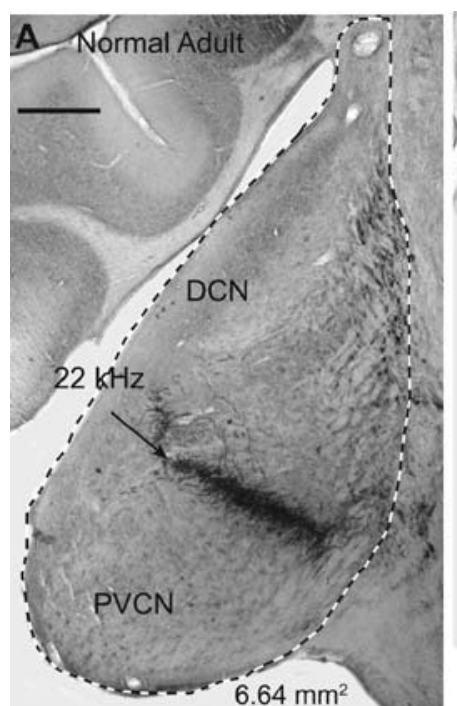

E
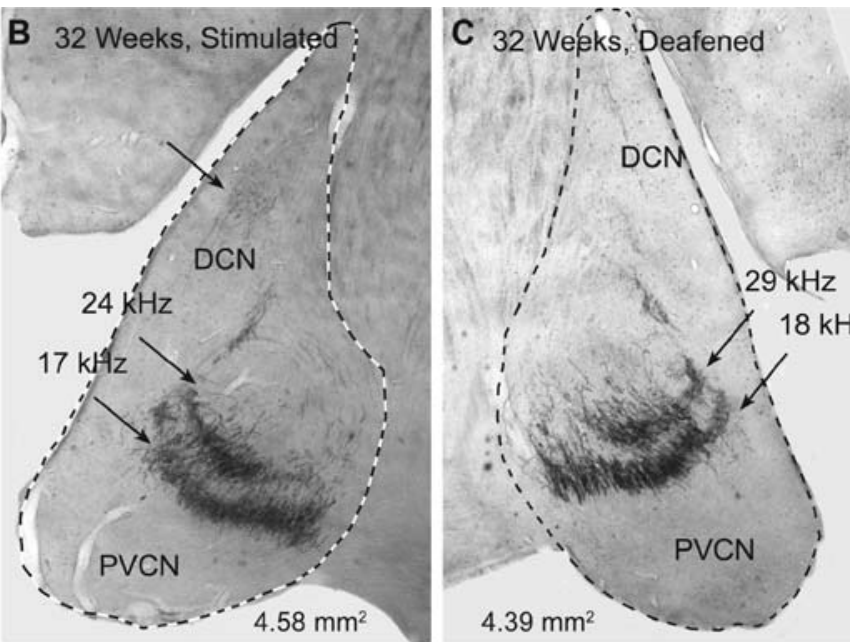

$29 \mathrm{kHz}$

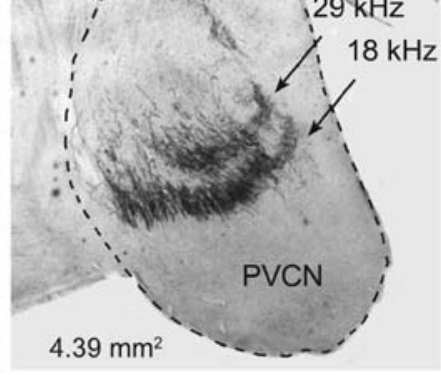

\section{z}

D 9 Weeks, Deafened

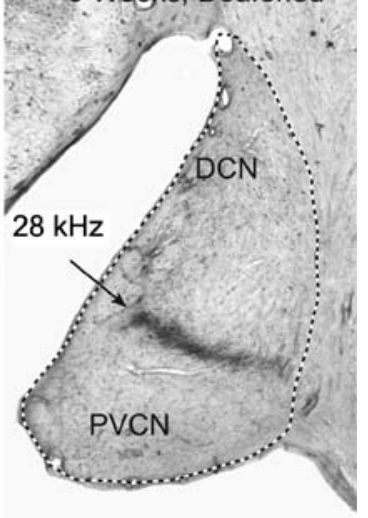

$2.97 \mathrm{~mm}^{2}$

\section{CN VOLUME}

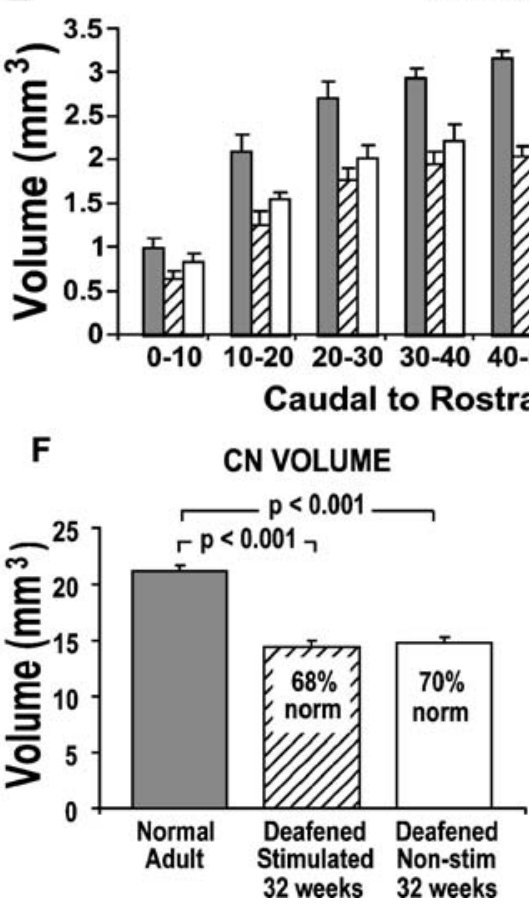

FIG. 3. The overall size of the $\mathrm{CN}$ was estimated by measuring its cross-sectional area in sections selected at $10 \%$ intervals and calculating overall volume (see "Methods"). To measure crosssectional area, the perimeter of the $\mathrm{CN}$ was traced as illustrated here in a normal adult (A), in a neonatally deafened subject (K158) examined after several months of electrical stimulation with the $\mathrm{CN}$ ipsilateral to stimulated cochlea shown in $\mathbf{B}$ and the other $\mathrm{CN}$ ipsilateral to non-stimulated ear shown in $\mathbf{C}$, and in a neonatally deafened subject at 9 weeks of age (D). Frequencies of injections/ projections were estimated from positions of cochlear injection sites. Scale bar $=0.5 \mathrm{~mm}$ and applies to A-D. Arrows indicate CN

implanted animals studied at $\sim 32$ weeks, the $\mathrm{CN}$ volume varied substantially from 12.5 to $16.1 \mathrm{~mm}^{3}$. The volumes of the stimulated (left side) and contralateral $\mathrm{CN}$ were virtually identical (means of 14.4 and $14.8 \mathrm{~mm}^{3}$, respectively) and were significantly smaller

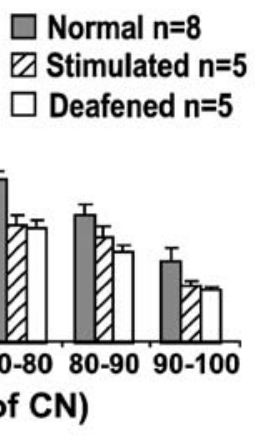

G

CN VOLUME

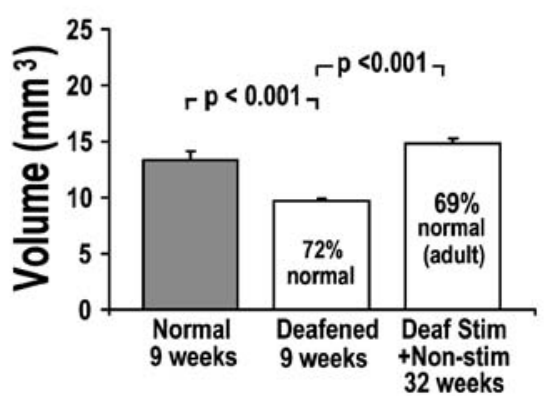

projections. E Volumes for $10 \%$ sectors of the $\mathrm{CN}$ in normal and both $\mathrm{CN}$ in the implanted, stimulated group, as calculated by multiplying the cross-sectional area measurements by the number of sections in each $10 \%$ interval and by section thickness $(50 \mu \mathrm{m})$. $\mathbf{F}$ Mean $\mathrm{CN}$ volume is shown for the normal adult control group and for both $\mathrm{CN}$ in the implanted group. $\mathrm{CN}$ volume was significantly smaller than normal on both the stimulated and the non-stimulated sides. G The $\mathrm{CN}$ volume in the deafened 9-week-old group was significantly smaller than that in normal animals examined at the same age and also smaller than the $\mathrm{CN}$ in the deafened 32 week-old group (mean of stimulated and non-stimulated sides).

than normal, averaging $68 \%$ and $70 \%$ of the $\mathrm{CN}$ volume in normal adult controls (Fig. 3E, F). In addition, the mean $\mathrm{CN}$ volume is shown for the six $\mathrm{CN}$ measured in four younger deafened animals studied at $\sim 9$ weeks of age (Fig. 3G) to provide control data at 
the approximate age of implantation of the older deafened group. The $\mathrm{CN}$ volume in this younger deafened group was significantly smaller than that of the $\mathrm{CN}$ in normal animals studied at this same age (eight CN from five animals, mean age at study 8.9 weeks) and also significantly smaller than the CN volume in the older deafened group.

The CN cross-sectional area data were also used to normalize $\mathrm{CN}$ projection thickness for each subject to take into account the difference in $\mathrm{CN}$ size between the deafened animals and normal controls. The square root of the mean area was calculated for sections from the $20-80 \%$ intervals in each subject as an estimate of the mean $\mathrm{CN}$ width/height and as a metric to convert the units of the normalizing measure to match the measurements of the $\mathrm{CN}$ projection laminae. These values were used to calculate the lamina widths predicted if $\mathrm{CN}$ projections in the deafened animals were precisely proportionate to those in normal adults. On average, the square root of the mean $\mathrm{CN}$ area for the older, deafened, and implanted group was 1.99, whereas for normal adults, this value was 2.29. Therefore, if proportionate, the thickness of $\mathrm{CN}$ projection laminae in deafened and implanted animals, on average, would be $87 \%(1.99 / 2.29)$ of those in adults. In the younger deafened group, the measured thickness of $\mathrm{CN}$ projection laminae would be predicted to be $78 \%(1.79 / 2.29)$ of those in adults. Individual predicted values calculated for $\mathrm{CN}$ projections in each deafened subject were compared statistically to the actual values measured for projections in each $\mathrm{CN}$ subdivision.

\section{Characterization of NB-labeled $\mathrm{CN}$ projections}

Despite the early deafness and unilateral broadly distributed electrical stimulation of the auditory nerve experienced by these experimental animals, the major subdivisions of all $\mathrm{CN}$ were still clearly defined and identifiable by their cytoarchitecture. Neurobiotinlabeled central axons of SG neurons were observed within the auditory nerve in discrete fascicles. After entering the cochlear nerve root, the fibers bifurcated into ascending and descending branches and projected to all three major subdivisions of the $\mathrm{CN}$. The ascending branches projected rostrally to terminate within the AVCN. The descending branches projected caudally to terminate within the PVCN and also gave off fine collaterals that projected medially and dorsally to the DCN. All projections appeared to be fully labeled at post-injection times as short as $7 \mathrm{~h}$. Moreover, the injections in all these deafened animals resulted in discrete bands or laminae of labeled fibers and terminals that always exhibited a clear, normal cochleotopic organization. SG injections made at more basal (higher frequency) locations produced projec- tion bands that were positioned dorsally within each CN subdivision, and apical injections resulted in labeled laminae projecting more ventrally in the $\mathrm{CN}$ (Figs. 3 and 5), as described previously in normal cats (Leake and Snyder 1989; Snyder and Leake 1997; Snyder et al. 1997), neonatal kittens (Leake et al. 2002), and deafened animals (Leake et al. 2006). Figure $3 \mathrm{~B}$ and $\mathrm{C}$ illustrate the projections to the stimulated (left side) and contralateral $\mathrm{CN}$ in one neonatal subject (K158), and they appear remarkably similar despite the robust electrical excitation of the auditory nerve and $\mathrm{CN}$ by the cochlear implant on the left side. Note that the basal channel of our implant is centered at about $15 \mathrm{kHz}$ (based on percent distance from the cochlear base) and thus was positioned in proximity to the SG neurons that were labeled by the $17-\mathrm{kHz}$ injection.

The characteristics of the auditory nerve fibers and terminals labeled by HRP in normal cats have described in detail previously (Ryugo and Fekete 1982; Fekete et al. 1984; Rouiller et al. 1986; Leake and Snyder 1989; Snyder et al. 1997; Leake et al. 2002). The axons of passage and pre-terminal axonal ramifications in the neonatally deafened CN generally appeared somewhat more sparse (i.e., had fewer fibers) and less intensely labeled in all subdivisions of the $\mathrm{CN}$ than in controls (Fig. 4). Nevertheless, numerous calyceal endings were identified in the deafened projections to the AVCN on both the stimulated and contralateral sides (Fig. 4A, B), which corresponded in appearance to the endbulbs of Held in normal cats (Ryugo and Fekete 1982; Limb and Ryugo 2000; Leake et al. 2006). In the PVCN, the labeled projections formed laminae that projected in the rostral to caudal plane and were comprised of large axons of passage and finer pre-terminal axons with occasional simple bouton and en passant swellings. Terminals that were quite similar in shape to the calyceal endings of the AVCN, as well as some smaller en passant boutons, were seen in these projections (Fig. 4C, D). Caudally, the fibers terminated in string-like endings oriented orthogonal to the projection bands. In the DCN and small cell cap, the terminal fields were composed of relatively sparse, fine pre-terminal axons exhibiting mostly small bouton endings (Fig. 4E, F). No obvious differences were seen between labeled projections ipsilateral to the stimulated cochleae and those from non-implanted cochleae.

\section{Measurements of $\mathrm{CN}$ projection laminae} in implanted, electrically stimulated animals

Measurements of $\mathrm{CN}$ lamina thickness were made to evaluate the selectivity of projections relative to the frequency gradient of each CN subdivision. Figure 5 illustrates the morphometric method for quantitative analysis of projections. All sections with clear laminae 

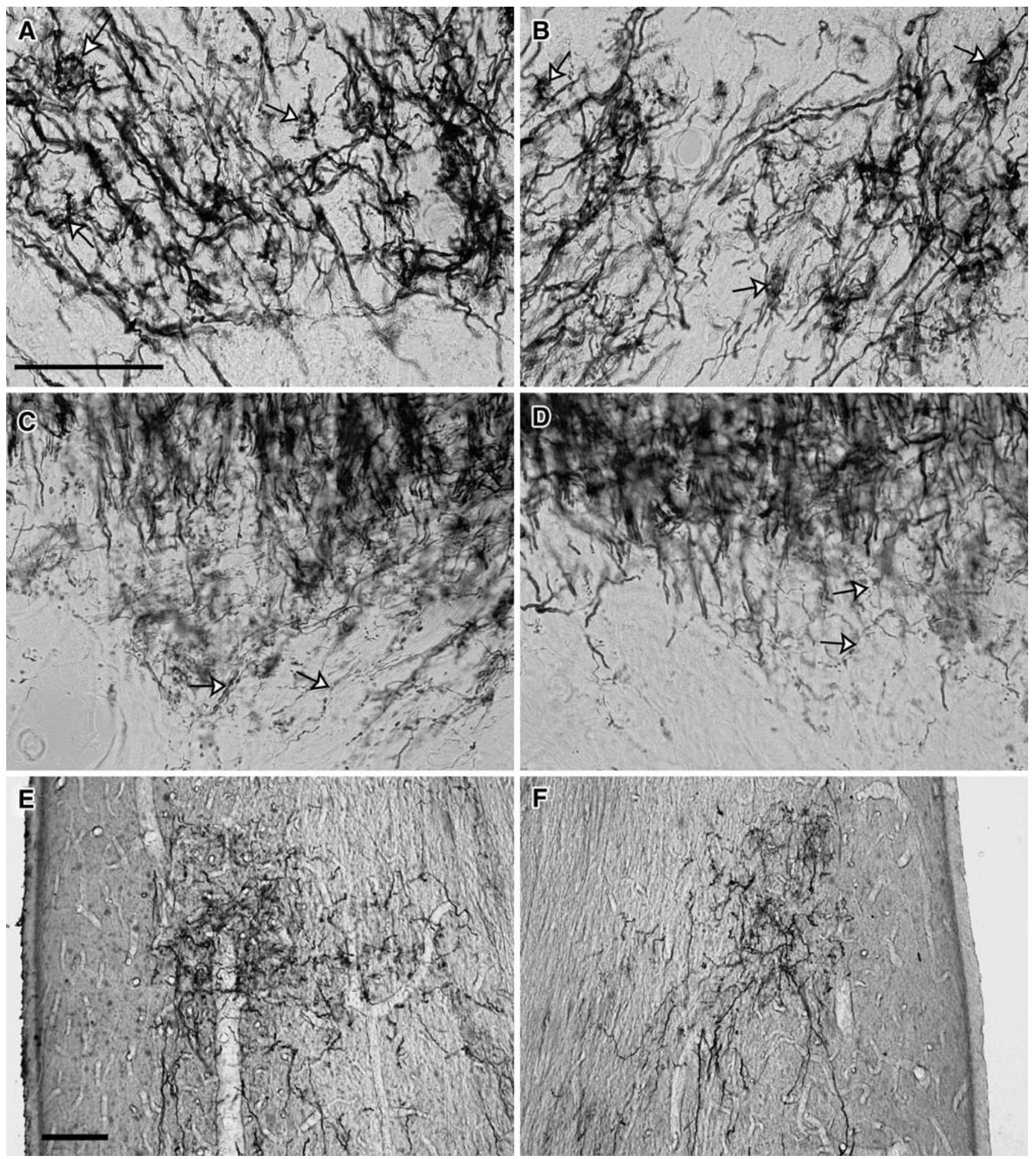

FIG. 4. A, B NB-labeled auditory nerve fibers in the AVCN projection lamina are shown on the stimulated side $(\mathbf{A})$ and on the contralateral side (B) in a neonatally deafened cat examined at about 41 weeks of age (K158) following 34 weeks of electrical stimulation from a cochlear implant. Arrows indicate auditory nerve calyceal endings, which appear to be relatively normal in light microscopy, although less dense than normal. C, D NBlabeled auditory nerve fibers in the PVCN are shown in the stimulated $\mathrm{CN}(\mathbf{C})$ on the left side and in the contralateral, nonstimulated $\mathrm{CN}$ (D) in the same neonatally deafened, implanted

animal. The images illustrate the complexity and density of the neuropil in PVCN and the fine string endings (arrows), which are seen passing ventrally from the main projection lamina along its caudal extent. E, F Labeled auditory nerve fibers in the DCN projection laminae are shown in the stimulated $(\mathbf{E})$ and nonstimulated $\mathrm{CN}(\mathbf{F})$ of the same subject, illustrating the fine caliber of labeled auditory nerve fibers and terminals in this region. Scale bar in $\mathbf{A}=100 \mu \mathrm{m}$ and indicates magnification for A-D; scale bar in $\mathbf{E}=100 \mu \mathrm{m}$ and also indicates magnification for $\mathbf{F}$. 
were imaged near the center of each projection, and three scans were made in each image by using a window positioned orthogonal to the projection lamina(e). Figure 5A shows one image used to evaluate PVCN projections in a deafened, stimulated $\mathrm{CN}$ along with one raw scan from this image (Fig. 5B, C) and the mean pixel density plot (Fig. 5D). The numerical distributions for all the scans were averaged, background density was subtracted, and projec-
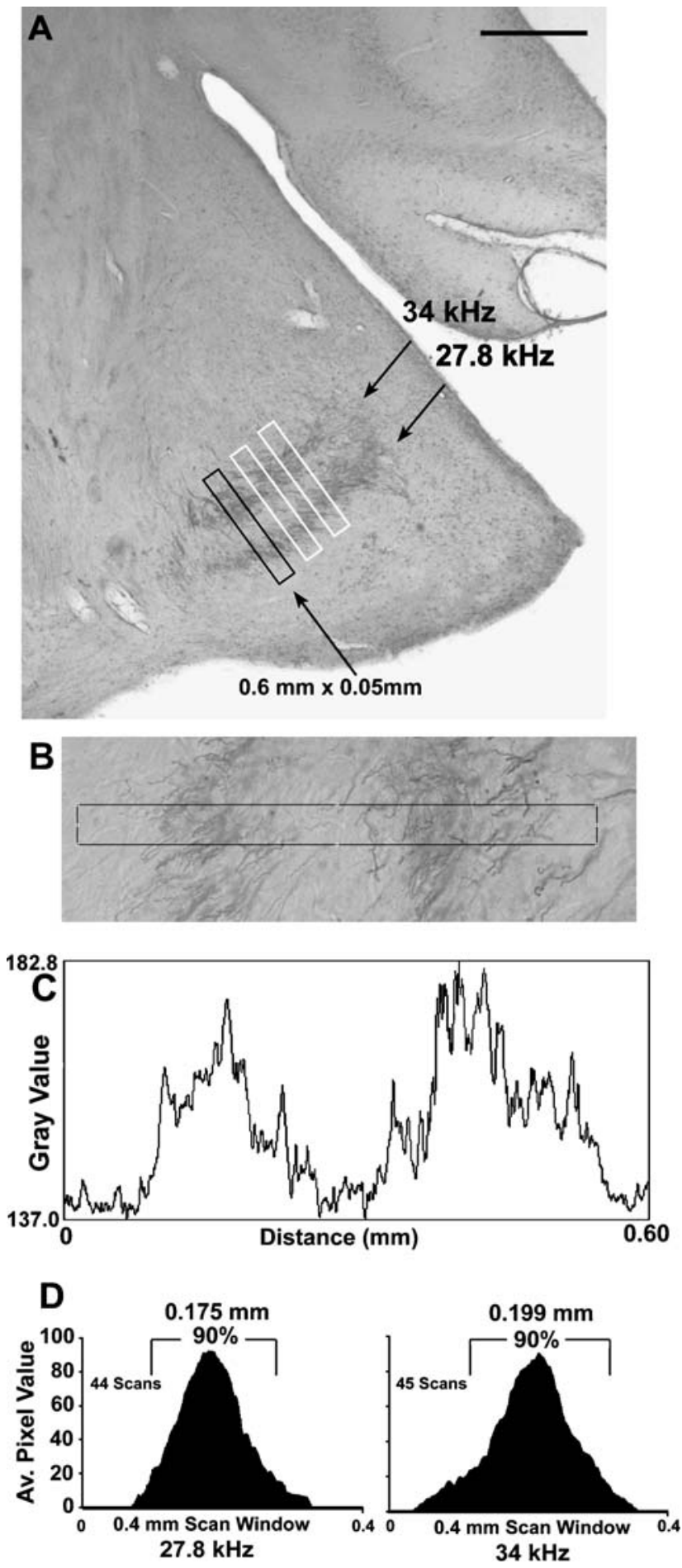

tion thickness was defined as the distance containing $90 \%$ of the total pixel density (Fig. 5D). This method was applied to obtain objective measurements of the projection widths in each $\mathrm{CN}$ subdivision.

Injections were made bilaterally in the five neonatally deafened, unilaterally stimulated animals (ten cochleae). Single injections were made in both cochleae of K154, and double injections were made in the four remaining subjects (total of 18 injections). However, not all injections produced measurable projections to all three $\mathrm{CN}$ subdivisions. In particular, after several months of cochlear implantation, the implanted electrodes often were encapsulated in dense fibrous connective tissue or bone that had to be dissected away from the modiolus before NB injections could be made. This pathology made it more difficult to identify Rosenthal's canal, and fewer injections in the implanted and stimulated ears produced projections that were labeled intensely enough to be measured, as compared to the non-stimulated side.

\section{AVCN projections}

A total of five projections to the stimulated AVCN and seven to the non-stimulated side were measured, as summarized in Figure 6A. Projection laminae in the stimulated AVCN averaged $0.250 \mathrm{~mm}$ in thickness across the $\mathrm{CN}$ frequency gradient. The projections in the contralateral AVCN were almost identical with a value of $0.258 \mathrm{~mm}$, and this small difference between sides was not statistically significant (Student's $t$ test). The absolute values of projection widths measured in both AVCN in the deafened and implanted animals were slightly larger than the corresponding thickness of projections in normal controls $(0.223 \mathrm{~mm} ; n=10$ projections measured in six $\mathrm{CN}$ ), but this difference was not statistically significant even when the projections in both stimulated and non-stimulated $\mathrm{CN}$ were pooled and compared to normal as a single group (Student's $t$ test).

As shown previously, the $\mathrm{CN}$ in the deafened animals was significantly smaller, and its volume averaged

4FIG. 5. A Projection thickness was estimated in digital images of the $\mathrm{CN}$ by determining the mean pixel density in windows of $0.6 \mathrm{~mm}(25$ pixels) by $0.04 \mathrm{~mm}$ (200 pixels). In each image, three scan windows were oriented with the long axes orthogonal to the projection lamina, and the scan was directed from apex to base along the cochleotopic axis. The section illustrated is from the PVCN in a deafened animal (K160R) studied at 34 weeks of age. B The first scan window from the section in $\mathbf{A}$ is shown at higher magnification. $\mathbf{C}$ Plot of the raw pixel values for scan in $\mathbf{B}$ as seen in Image J (inverted such that black $=255$, white $=0$ ). $\mathbf{D}$ The averaged pixel value plots are shown for the two projections. Threshold level was set by subtracting background gray value until the first negative value occurred in the window. The average plot was normalized, and projection thickness was calculated as the distance containing $90 \%$ of the total pixel value, which was $0.175 \mathrm{~mm}$ for the $27.8 \mathrm{kHz}$ projection and $0.199 \mathrm{~mm}$ for the $34 \mathrm{kHz}$ projection illustrated. Scale bar in $\mathbf{A}=0.5 \mathrm{~mm}$. 


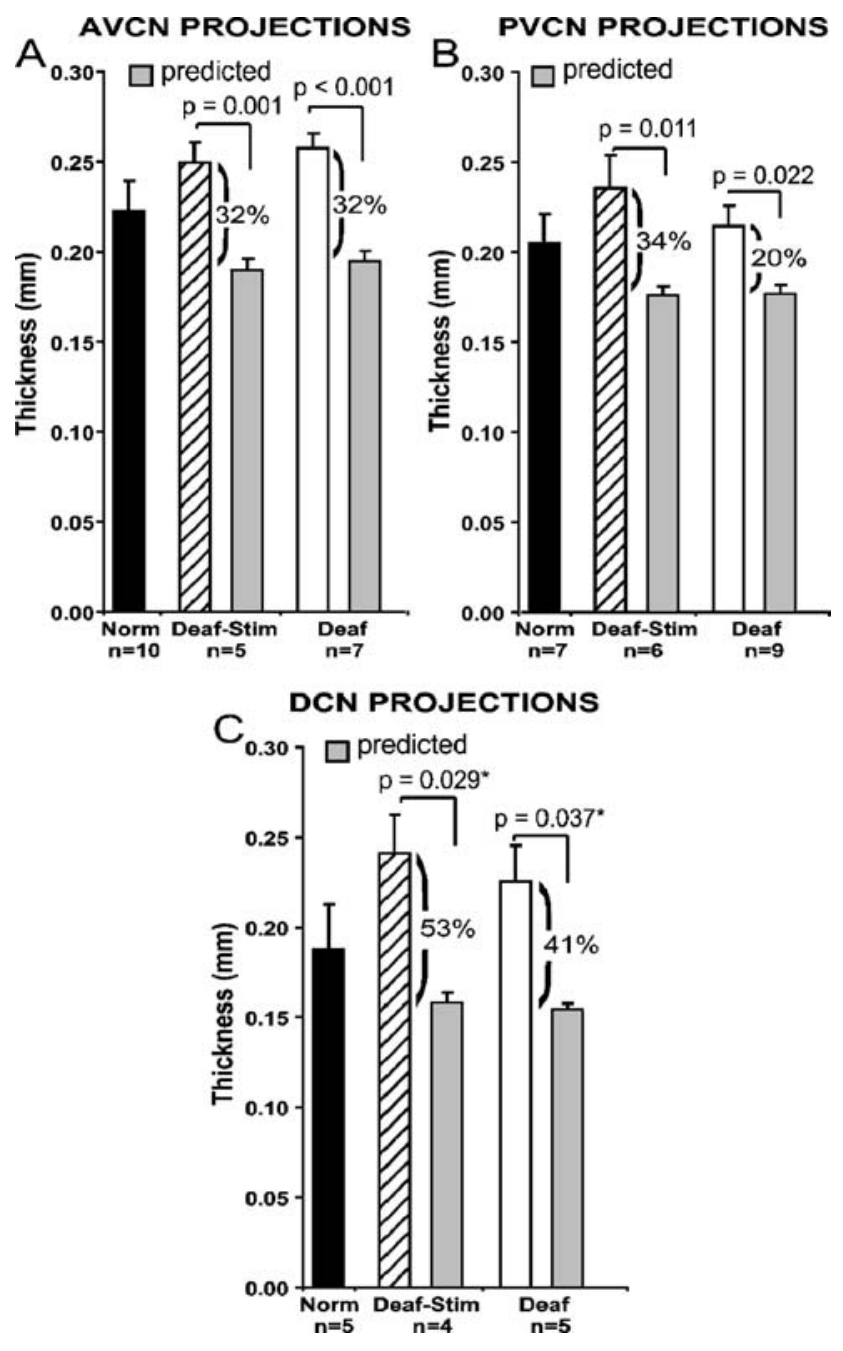

about $70 \%$ of that measured in normal adult controls. To normalize for CN size, we divided the AVCN projection thickness in each $\mathrm{CN}$ by the square root of the mean $\mathrm{CN}$ areas measured in the $20-80 \%$ region (see "Methods"). In normal adults, this ratio averaged $0.097(0.223 / 2.29)$. If the $\mathrm{CN}$ and its AVCN projections in deafened animals were proportionately reduced in size, then this ratio should be the same in deafened subjects. For example, the mean square root of $\mathrm{CN}$ area on the stimulated side was $1.95 \mathrm{~mm}$, and the average "predicted" AVCN projection thickness if proportionate to normal would be $x=0.097 \times 1.95$ or $0.189 \mathrm{~mm}$ (Fig. 6A). Instead, the measured AVCN projections averaged $\sim 32 \%$ broader $(0.250 \mathrm{~mm})$ in the stimulated $\mathrm{CN}$ and $34 \%$ broader $(0.258 \mathrm{~mm})$ in the deafened non-stimulated $\mathrm{CN}$ than would be predicted by the scaling calculations. These differences were highly significant (Student's $t$ test; $p<0.001$ ).

\section{PVCN projections}

In these same deafened/implanted experimental animals, a total of six PVCN projections were measured on the stimulated side, and all nine projections were
FIG. 6. Mean $\mathrm{CN}$ projection measurements are presented for normal adult controls (black bars) and for the stimulated (striped bars) and non-stimulated $\mathrm{CN}$ (clear bars) of neonatally deafened, implanted animals studied at $\sim 32$ weeks of age. In the deafened animals, there was no difference between the stimulated and contralateral sides in $\mathrm{CN}$ projections measured in the AVCN, PVCN, or in DCN. A The mean AVCN projection thickness in both deafened $\mathrm{CN}$ was slightly larger than normal $(0.223 \mu \mathrm{m})$, but these small differences were not significant. When normalized for the smaller $\mathrm{CN}$ in the deafened animals, the AVCN projections were $32 \%$ broader in both the stimulated $\mathrm{CN}$ and contralateral $\mathrm{CN}$ than the values predicted if these projections were proportionate to AVCN projections in normal control subjects (shaded bar). These differences were highly significant. B The PVCN projection laminae in normal controls had a mean thickness of $205 \mu \mathrm{m}$, and projections in the deafened PVCN were not significantly different. However, when normalized for the smaller size of the $\mathrm{CN}$ in deafened animals, the measured PVCN projection thickness was $34 \%$ broader in the stimulated $\mathrm{CN}$ and $20 \%$ broader in the non-stimulated $\mathrm{CN}$ than the values predicted if projections were proportionate to normal controls. C The DCN projection laminae in normal controls averaged $188 \mu \mathrm{m}$. The measured values for DCN projection thicknesses in the deafened subjects were slightly larger than those of normal adult cats, but again these differences were not statistically significant. When normalized for $\mathrm{CN}$ size, the DCN projections in the deafened animals were $53 \%$ (stimulated $\mathrm{CN}$ ) and $41 \%$ (non-stimulated contralateral $\mathrm{CN}$ ) broader than predicted if proportionate to normal adults. Error bars Standard error. The Student's $t$ test (unpaired) was used for comparisons of projections in deafened and control subjects and for comparisons with predicted values, except when the data failed the $t$ test assumption of normality (equal variance) in which case the Mann-Whitney rank sum test $(*)$ was used.

measured in the contralateral CN (Fig. 6B). PVCN projections had a mean thickness of $0.235 \mathrm{~mm}$ on the stimulated side and $0.214 \mathrm{~mm}$ for the contralateral non-stimulated CN. This small difference between sides was not significant, and when the data from the stimulated and contralateral PVCN projections were pooled, they were not significantly different from normal (mean, $0.205 \mathrm{~mm}$.) However, when normalized for the smaller size of the $\mathrm{CN}$, the PVCN projections in the stimulated $\mathrm{CN}$ were $34 \%$ broader than predicted, and projections to the contralateral $\mathrm{CN}$ were $20 \%$ broader than would be predicted if they were precisely proportionate to normal adult PVCN projections. These differences between measured and predicted values for PVCN projections were statistically significant (Student's $t$ test or Mann-Whitney rank sum test; $p=0.011$ stimulated CN; $p=0.022$ deafened $\mathrm{CN}$ ).

\section{DCN projections}

The fibers projecting to the DCN are very fine in caliber and also have the longest distance to travel from the injection sites in the SG, which tended to reduce the yield of projections that could be measured in the DCN. Four DCN projections in the stimulated $\mathrm{CN}$ and five DCN projections in contralateral deafened $\mathrm{CN}$ of three animals were measured (Fig. 6C). The DCN projections ipsilateral to the stimulated cochlea had a mean 
thickness of $0.241 \mathrm{~mm}$, and projections from the nonstimulated cochlea had a mean thickness of $0.225 \mathrm{~mm}$. This difference was not statistically significant. In normal controls (five projections in five $\mathrm{CN}$ ), the DCN projections averaged $0.188 \mathrm{~mm}$. The absolute values for DCN projection thicknesses in deafened subjects were slightly larger than the corresponding normal values, but these differences were not statistically significant. When normalized for CN size, DCN projections in the deafened implanted animals were $53 \%$ broader on the stimulated side and $41 \%$ broader on the contralateral side than predicted if they were proportionate to normal DCN projections. Again, these differences between the measured and predicted (proportionate) projection widths were statistically significant (MannWhitney, $p=0.029$ for projections in the stimulated $\mathrm{CN}$; $p=0.037$ for the contralateral $\mathrm{CN}$ ).

Measurements of $\mathrm{CN}$ projections at 9 weeks of age in deafened animals

Figure 7 presents the data for $\mathrm{CN}$ projections measured in the younger deafened group studied at an average age of 9 weeks, in comparison to both normal adult controls and to the older deafened, implanted group (data are pooled from the stimulated and nonstimulated $\mathrm{CN}$ because there was no difference between them). Interestingly, there is no significant difference between the projection thickness values measured in AVCN (0.262 mm), PVCN (0.199 mm), or DCN (0.221) in the younger deafened group as compared to the respective projections measured in the older deafened, implanted group studied at $\sim 32$ weeks of age (AVCN 0.254; PVCN 0.223; DCN 0.232). Moreover, CN projection thicknesses measured in the all three $\mathrm{CN}$ subdivisions of the 9 week-old group also were not significantly different from projections measured in normal adult controls.

When normalized for the much smaller $\mathrm{CN}$ size in the deafened 9 week-old animals, AVCN projections were broader by $51 \%$ than predicted if they were proportionate to AVCN projections in normal adults, PVCN projections were $25 \%$ broader, and DCN projections were $50 \%$ broader than predicted. These differences between the measured projections and the predicted proportionate projection widths in each subdivision were highly significant (Student's $t$ test or Mann-Whitney).

\section{Density of projections}

Figure 8 illustrates the mean pixel densities for projections measured in the AVCN, PVCN, and DCN of normal adult controls and in neonatally deafened, implanted animals studied at $\sim 32$ weeks of age. There was no difference in pixel densities between $\mathrm{CN}$

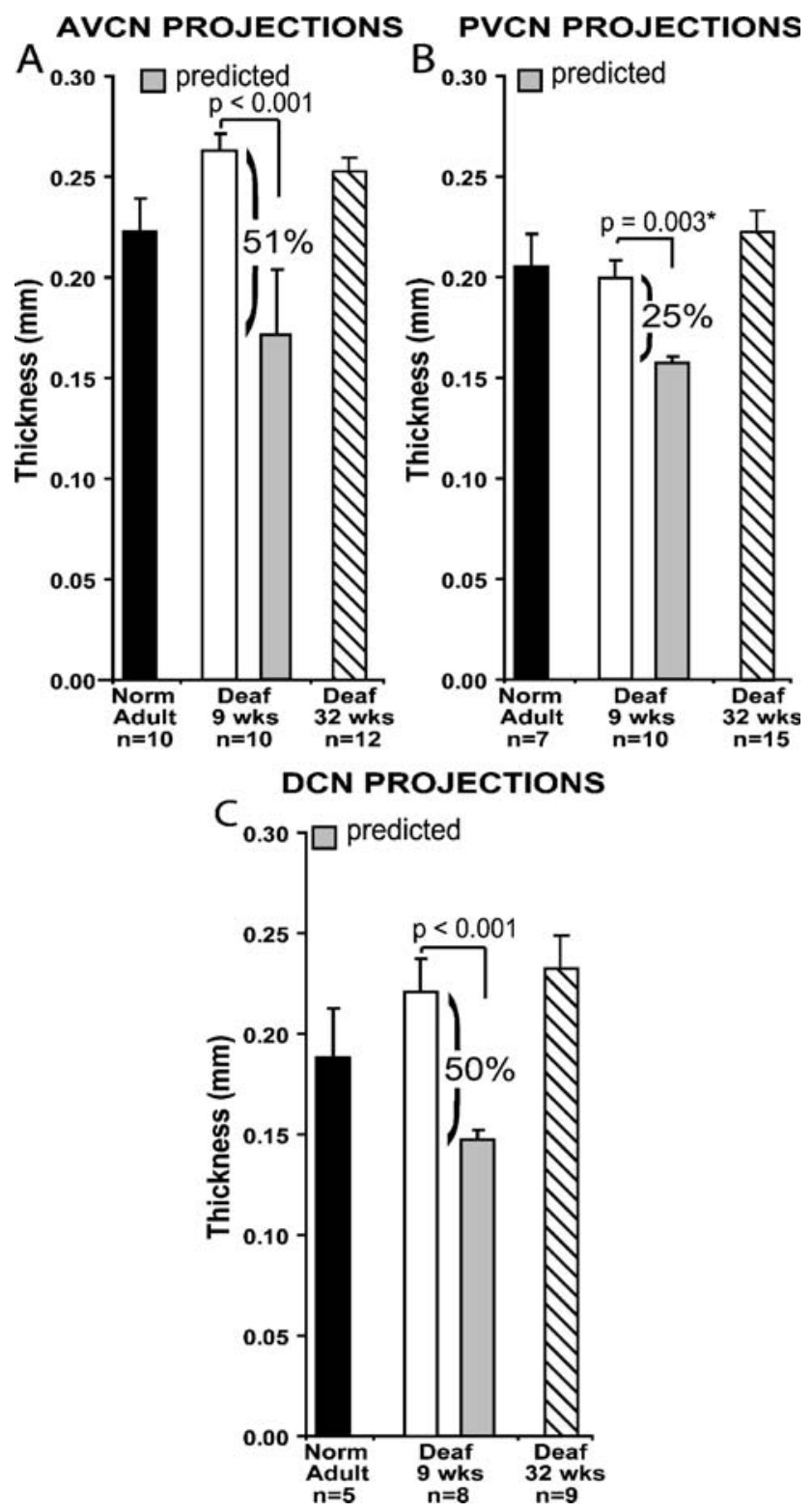

FIG. 7. Mean projection thicknesses measured in AVCN, PVCN, and DCN in the neonatally deafened animals examined at 9 weeks of age (open bars) were not significantly different from projections in normal adult controls (black data bars) and also were not significantly different from projections measured in the older deafened, implanted group (mean of both $\mathrm{CN}$, striped bars). When normalized for the much smaller $\mathrm{CN}$ in the 9-week-old group, measured projections were significantly broader than values predicted if they were proportionate to the respective projections in the normal control subjects (black bars) in the AVCN (51\% broader, A), PVCN (25\% broader, B), and DCN (50\% broader, C). Error bars indicate standard error of the mean. The Student's $t$ test (unpaired) was used for comparisons of projections in deafened and control subjects and also for comparisons with predicted values, except when the data failed the $t$ test assumption of normality (equal variance) in which case the Mann-Whitney rank sum test $\left({ }^{*}\right)$ was used.

projections from the stimulated cochlea and the $\mathrm{CN}$ projections from the non-implanted ear. Therefore, the data from both sides have been pooled for comparison to the respective projection densities in 


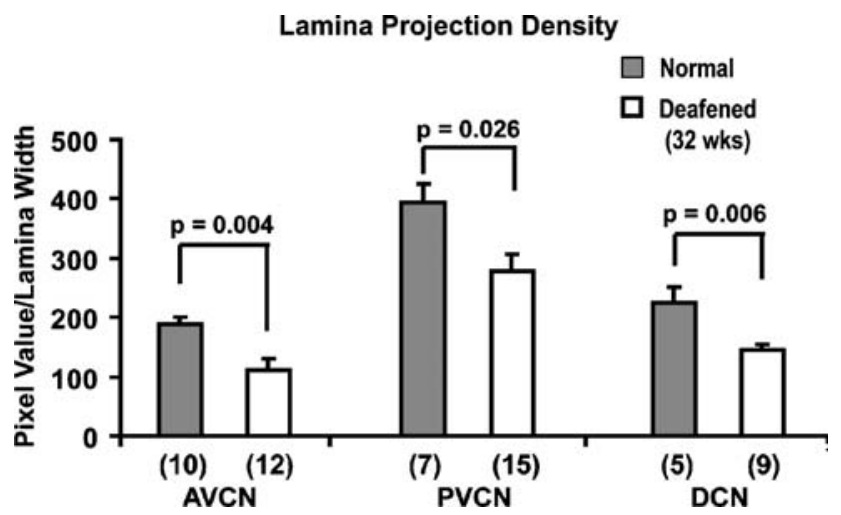

FIG. 8. Average pixel density values for all scans of projections are compared for normal controls and deafened groups in each $\mathrm{CN}$ subdivision. In all three subdivisions, AVCN and PVCN and DCN, pixel densities are significantly reduced in the deafened subjects (mean of stimulated and non-stimulated sides in animals studied at 32 weeks of age) as compared to normal adult controls. Error bars represent standard error of the mean.

normal cats. These data demonstrate that pixel density is significantly higher in normal animals than in the deafened projections to each of the three $\mathrm{CN}$ subdivisions (Student's $t$ test, unpaired), as expected due to the significant reduction in the SG cell populations projecting to the $\mathrm{CN}$ in deafened animals.

\section{DISCUSSION}

The main goal of this work was to examine the topographic specificity of the neural projections from the cochlear spiral ganglion to the cochlear nuclei in animals that had undergone profound hearing loss early in life and received a unilateral cochlear implant at about 7 weeks of age. To our knowledge, this is the first study of the specificity of the auditory nerve projections after chronically applied electrical stimulation in an animal model of congenital profound hearing loss. Our findings help to elucidate the role of normal auditory experience and the effects of early deafness and electrical stimulation from a cochlear implant on the development and maintenance of the precise cochleotopic maps formed by the primary afferents within the $\mathrm{CN}$.

Molecular mechanisms, neuronal activity, and tonotopic map formation

It is generally agreed that neural activity is not involved in the initial formation of topographically ordered sensory pathways. However, there is little agreement about the specific roles of molecular cues and neuronal activity in the subsequent development and refinement of various topographic maps in the central nervous system (Rubel and Cramer 2002). In the auditory system, several lines of evidence suggest that patterns of neural connections are essentially correctly organized from the time of their initial arrival at target locations (Rubel and Fritzsch 2002). In chickens, a tonotopically ordered map of the auditory nerve axons projecting within the $\mathrm{CN}$ analogue (nucleus magnocellularis) is present from early embryonic ages, even before the formation of hair cell synapses (Molea and Rubel 2003). Our previous study in cats demonstrated a clear cochleotopic order of SG projections in the $\mathrm{CN}$ of kittens examined as young as several days prenatal (Leake et al. 2002), well before hearing onset. Moreover, studies in mutant mice have demonstrated that at least a rudimentary cochleotopic order is established in connections from the SG, even in the absence of differentiated hair cells (Xiang et al. 2003), and central projections can maintain relatively normal organization despite massive rerouting of fibers in the periphery, as seen in Ntf3 ${ }^{\text {tgBDNF}}$ mice in which vestibular fibers project to the cochlea (Fritzsch et al. 2005).

Recent studies of the molecular mechanisms underlying the establishment of auditory brainstem circuits have demonstrated that Eph protein gradients are important in the formation of tonotopic projections (e.g., from the auditory nerve to the nucleus magnocellularis and from the nucleus magnocellularis to the nucleus laminaris) in chicks and suggesting that Eph signaling may be a conserved mechanism for establishing topographic specificity in diverse sensory systems (Person et al. 2004; Siddiqui and Cramer 2005; see Cramer 2005 for review). Thus, relatively accurate tonotopic maps likely form initially through processes independent of activity and guided by specific molecular mechanisms (Rubel and Fritzsch 2002; Fritzsch et al. 2005, 2006). Eph/ephrin signaling is of particular interest because of its well-established role in formation of topographic maps in other sensory systems, including the visual system (Feldheim et al. 2000), the somatosensory (Prakash et al. 2000), and olfactory systems (Cutforth et al. 2003).

However, after the initial pathway formation, some sensory systems exhibit significant refinement of connections during late prenatal or early postnatal development, with projecting axons undergoing "pruning" of their axonal domains, resulting in more precise topographic maps of the afferent input (LeVay et al. 1978; Cowan et al. 1984; Easter et al. 1985; Sachs et al. 1986; Shatz 1996), with some examples reported in the auditory system (Jackson and Parks 1982; Young and Rubel 1986; Friauf and Lohmann 1999; Leake et al. 2002). As outlined in the "Introduction", some studies of visual system development have emphasized that neuronal activity plays a critical role in this topographic refinement (Shatz 1996). Competition among ganglion cells is thought to influence the size of 
terminal arbors of retinogeniculate neurons (Sur et al. 1984; Friedlander and Tootle 1990), and interocular competition is required for normal segregation and refinement of projections from the two eyes (LeVay et al. 1978; Sretavan and Shatz 1986, 1987). Specific spatiotemporal patterns of spontaneous and visual input have been shown to guide the formation of precise synaptic connections (Zhou et al. 2003; Chiu and Weliky 2003), and the progressive refinement of visual receptive fields in the tectum involves an activitydependent matching of the topography and strengths of excitatory and inhibitory connections (Tao and Poo 2005).

The SG-to-CN projections are of particular interest for studying the role of neuronal activity in the development of topographic maps because their precise organization forms the basis for the tonotopic organization that is maintained at each successive level throughout the central auditory system. Each auditory nerve axon sends collaterals to all three $\mathrm{CN}$ subdivisions, where their specialized terminal arborizations provide the basis for all initial signal processing in the central auditory system. Because the cat auditory system is altricial, it provides an excellent opportunity to study the topography of projections before and during the emergence of initial function in the primary afferents. At birth, the cat auditory system is so immature that it is essentially non-functional. Behavioral thresholds are extremely high (Foss and Flottorp 1974; Clements and Kelly 1978; Ehret and Romand 1981), and spontaneous activity cannot be recorded reliably in auditory nerve fibers until several days postnatal (Romand 1984; Walsh and McGee 1986; Jones et al. 2007). Auditory nerve fibers thresholds remain high, tuning is broad, and spontaneous discharge rates are very low (mean $<10$ spikes/s) until at least P8 to P10 (Romand 1984; Dolan et al. 1985; Walsh and McGee 1986, 1990; Walsh and Romand 1992). During the first postnatal week, sound-evoked discharges in the auditory nerve and $\mathrm{CN}$ display rhythmic, bursting patterns in response to long-duration acoustic stimuli (Pujol 1972; Walsh and McGee 1987; Fitzakerley et al. 1995, 1998; Walsh et al. 1998), and this activity is markedly different from the random interspike intervals seen in adult auditory nerve fibers (Kiang et al. 1965).

\section{Postnatal refinement of auditory nerve projections to the $\mathrm{CN}$}

In a previous study, we used the same methods employed here to study the normal development of the SG-to-CN projections in kittens from $\mathrm{P} 6-\mathrm{P} 45$ (Snyder and Leake 1997) and found that the topographic specificity of projections in each of the three major $\mathrm{CN}$ subdivisions is about as precise in $\mathrm{P} 6-7$ kittens as in adults. In contrast, projections in neonates (or in late gestation) are proportionately broader in their distributions across the $\mathrm{CN}$ frequency gradient than adult projections (Leake et al. 2002). AVCN projections (normalized for $\mathrm{CN}$ size) were more than $50 \%$ broader than their adult counterparts, and both PVCN and DCN projections were broader by more than $30 \%$ in neonates. Further, two injections that were well-separated in the cochlea resulted in AVCN projections that were incompletely segregated and fused PVCN projections in subjects studied after cesarean section at 2-3 days before the average day of birth. Thus, significant refinement in the primary auditory nerve projections occurs during the postnatal period immediately prior to the onset of hearing (i.e., the period when bursting activity is observed in auditory nerve and $\mathrm{CN}$ responses). On the other hand, a clear tonotopic order of the projections to all three CN subdivisions was evident even in the youngest animals examined. Thus, despite the greater extent of spatial overlap of projections demonstrated by quantitative analysis, the clear tonotopic order and relative selectivity exhibited by the SG inputs to the $\mathrm{CN}$ at this stage of development are noteworthy.

\section{Neonatally deafened cats}

In animals deafened for this study, daily neomycin injections were started at birth and continued for 1824 days until ABR testing demonstrated profound hearing loss. Thus, the ototoxic drug is administered prior to and during the time when hearing onset would normally occur and results in virtually total loss of hair cells throughout the cochlea by the time profound hearing loss occurs (Leake et al. 1997). Neomycin injections had to be continued beyond the first ABR testing at P16 in all subjects, indicating that some highthreshold acoustic responses were still present at this time, but these animals clearly were severely deprived of normal auditory experience from birth. It is unclear whether spontaneous activity develops and/or persists in the auditory nerve in deafened animals, but even if some spontaneous activity does develop initially, it seems unlikely that it could be maintained for long given complete hair cell loss. Electrophysiological studies in animals acutely deafened by ototoxic drugs have indicated that auditory nerve fibers do not exhibit spontaneous activity (Hartmann et al. 1987; Parkins 1989), whereas two studies in chronically deafened animals have reported some highly aberrant spontaneous activity (Hartmann and Klinke 1989; Shepherd and Javel 1997). It seems reasonable to assume that the deafened non-stimulated $\mathrm{CN}$ was largely deprived of direct input throughout the animals' lives and that the activity elicited by the cochlear implant beginning at 7 weeks of age provided the only major input to the deafened auditory system. 
Auditory nerve projections after chronic electrical stimulation

An important finding in the present study is that the cochleotopic organization of the primary afferent auditory nerve (SG) input to the $\mathrm{CN}$ is well developed at 9 weeks of age in neonatally deafened animals and is maintained essentially unchanged into adulthood, confirming and extending the results of our previous study (Leake et al. 2006). It is noteworthy that the $\mathrm{CN}$ projections in all the deafened $\mathrm{CN}$ examined formed discrete "frequency band laminae," with a clear cochleotopic gradient and normal orientation from dorsal to ventral within each $\mathrm{CN}$ subdivision, despite profound bilateral auditory deprivation and lack of normal auditory input throughout life. Furthermore, projections to the $\mathrm{CN}$ ipsilateral to a cochlear implant that broadly activated the auditory nerve and central auditory system over periods of several months were indistinguishable from projections to the contralateral CN from the non-stimulated ear, and projections from two injections in a single cochlea always formed segregated projections into each $\mathrm{CN}$ subdivision. The maintenance of topographic specificity of the auditory nerve input to the $\mathrm{CN}$ supports the finding in previous electrophysiological studies suggesting that animals deafened by this same protocol exhibit relatively normal cochleotopic organization in the auditory midbrain when studied in adulthood (Snyder et al. 1990; Leake et al. 2000). However, those studies also demonstrated that aberrant electrical stimulation of the cochlea (e.g., stereotyped signals delivered on a single channel of a cochlear implant) can significantly distort and expand the central representation of the stimulated channel within the IC.

From this perspective, our data on the specificity of projections in implanted animals argue strongly for an inherent stability in the organization of the primary afferent projections. The classic studies of Moore and Kitzes (Kitzes et al. 1995; Kitzes 1996; Moore and Kitzes 1985; Moore and Kowalchuck 1988) showed that adult animals studied after neonatal removal of one cochlea exhibited substantial reorganization of the central auditory projections, with projections from the intact CN more than doubling in size in their distributions to the ipsilateral IC and forming highly ectopic projections to the superior olivary nuclei and the medial nucleus of the trapezoid body. Our present study provides a parallel experimental paradigm in that animals were deafened as neonates: One ear remained deaf throughout life, but the other ear was strongly activated by electrical stimulation beginning at 7 weeks of age and continuing to adulthood. The findings of equivalent $\mathrm{CN}$ frequency band projections on stimulated and deafened sides and absolute widths similar to normal animals provide evidence that there is no major reorganization, formation of ectopic projections, or massive expansion of the primary afferent neural pathways equivalent to changes seen by Moore and Kitzes at higher levels of the central auditory system.

On the other hand, although the SG-to-CN projections in deafened animals formed discrete laminae and exhibited clear spatial segregation, our data also showed that the projection laminae were proportionately broader than normal in both $\mathrm{CN}$ of the deafened, implanted subjects. This result is largely due to the fact that the size of the $\mathrm{CN}$ was markedly smaller than normal in neonatally deafened animals. When $\mathrm{CN}$ projection laminae in deafened animals were normalized for the smaller CN size, projections to all three $\mathrm{CN}$ subdivisions were proportionately broader than in normal controls. AVCN projections were $32 \%$ broader than normal on both the stimulated and contralateral sides in their relative distributions across the $\mathrm{CN}$ frequency gradient. PVCN laminae averaged $34 \%$ (stimulated $\mathrm{CN}$ ) and 20\% (non-stimulated side) broader than normal, and DCN projections were 53\% and $41 \%$ broader than normal in the stimulated and contralateral CN, respectively. Although the data suggest a larger difference in the DCN projections than in the VCN, we believe that this is an artifact of the NB labeling technique rather than a real difference in connectional selectivity because the fibers to the DCN are fine and have longer trajectories from the SG. NB must be transported over a longer distance to label them, and the yield of DCN projections labeled sufficiently for measurement was less than for the other subdivisions. Because there is also some inter-subject variability in injection size, we suggest that the larger DCN difference is due to the more limited number of cases with adequate labeling of DCN fibers and the likelihood that larger injections would better label these fine projections and also result in broader DCN projection widths.

The finding of a markedly smaller CN size in neonatally deafened animals, coupled with the evidence that the SG-to-CN projections in all deafened subjects have widths across the frequency gradient that are similar to those in normal animals (but proportionately broader), indicates that the projections from adjacent sectors of the SG must be more overlapping in these deafened subjects. Our interpretation of these findings is that the topographic specificity of the SG projections to the $\mathrm{CN}$ may be significantly degraded after deafness occurring early in life. Because CN projections representing adjacent frequencies in the SG are more overlapping in deafened animals, we infer that the selectivity of the cochleotopic map underlying frequency resolution within the $\mathrm{CN}$ also may be less precise (e.g., for discrete stimulation delivered by multiple channels of a cochlear implant). Interestingly, the extent to which $\mathrm{CN}$ projections were proportionately broader in these neonatally deafened animals is quite 
similar to results in normal neonatal kittens as described previously (Leake et al. 2002). When deafness occurs at a young age, the $\mathrm{CN}$ fails to grow to its normal adult size, whereas the $\mathrm{CN}$ projections appear to attain their normal adult dimensions, perhaps due to an intrinsic tendency for the SG projections to develop axonal arbors of a specific size. Thus, the imprecision in the topographic specificity of the SG-to$\mathrm{CN}$ projections that occurs during early postnatal development may be maintained (or reestablished) in adulthood due to the failure of the $\mathrm{CN}$ to achieve normal size when the auditory system is severely deprived of early normal auditory experience. The finding of equivalent projection widths on the stimulated and contralateral sides suggests that neuronal activity elicited by electrical stimulation from a cochlear implant beginning at 7 weeks postnatal (at least the particular stimulation paradigms applied here) is not sufficient to promote normal growth of the $\mathrm{CN}$ or for development and maintenance of normal topographic precision of the SG-to-CN projections. Perhaps this is not surprising because the electrical stimulation also failed to maintain normal SG survival. Given that bursting spontaneous activity in the auditory nerve and refinement of $\mathrm{CN}$ projections occur before hearing onset, it is also possible that auditory nerve activity must occur within a limited time frame or must more precisely replicate normal input (e.g., must be delivered with specific temporal patterns across frequencies) and that the electrical stimulation in our study took place too late or was too crude to effectively promote normal $\mathrm{CN}$ growth and precise refinement of the $\mathrm{CN}$ frequency band laminae. It would be interesting to address this issue in the future by introducing electrical stimulation at a very young age. However, it must be emphasized that with respect to clinical relevance, the present study provides a reasonable model of the practical limitations for the application of cochlear implants in the pediatric population (implantation $\sim$ a month after deafness occurs), especially because the onset of hearing in humans occurs in utero.

In this regard, it is important to remember that SG density was reduced by more than $50 \%$ in both ears of the deafened/implanted animals. If it were possible to implement a protocol (e.g., electrical stimulation combined with exogenous administration of neurotrophic agents) that maintained more nearly normal SG survival, perhaps closer to normal $\mathrm{CN}$ size and projections also would be maintained. Our previous studies have demonstrated that electrical stimulation can partially prevent SG degeneration in cats deafened by the same protocol (Leake et al. 1999, 2007), but in the present study, there was no difference between stimulated and non-implanted cochleae. At least two factors compromised survival in the stimulated ears in the present study. First, one implanted cochlea
(K160L) exhibited inflammation and infection that obviously impacted SG survival in that cochlea, which had the lowest SG survival of all the studied ears. In our previous studies of the trophic effects of stimulation, this animal would have been eliminated due to the infection, but because successful NB injections were made on both sides, the data are included here. Secondly, as mentioned earlier, the NB injections per se compromised SG survival in the base of the cochlea, where the largest stimulation-induced differences are typically seen. Schweitzer and Cecil (1992) studied the development of the central terminal arbors of individual labeled auditory nerve fibers in the DCN (in hamsters) and suggested that terminal fields are relatively restricted at birth and actually expand as the animal matures. In agreement with their findings, our previous study showed that absolute widths of projection laminae in all the $\mathrm{CN}$ subdivisions in neonatal kittens are smaller than those in adults, although when the small size of the $\mathrm{CN}$ is taken into account, the kitten projections are proportionately broader than those in adults (Leake et al. 2002). Together, the available data suggest that the increased precision of the $\mathrm{CN}$ frequency map with maturation results primarily from growth of the $\mathrm{CN}$ relative to the size of the auditory nerve terminal arbors rather than by retraction of initially large arbors. The initial overlap observed in the projections to adjacent frequency band laminae normally sharpens to adultlike precision during the first postnatal week, but in deafened animals, the $\mathrm{CN}$ fails to achieve normal adult size, resulting in normal-sized projection laminae that are more overlapping in the deafened CN. It is conceivable that nearest neighbor SG neurons actually maintain the precision of their synaptic specificity in the deafened $\mathrm{CN}$, such that the proportionately broader projections observed in our NB labeling studies represent an interdigitation of adjacent frequency band laminae. However, given the severe degeneration that occurs in the $\mathrm{CN}$ after neonatal deafening, we propose the more conservative interpretation that the proportionately broader distribution relative to the cochleotopic gradient represents a reduction (degradation) in the specificity of the topographic map. Further, previous studies have shown that the target neurons in the $\mathrm{CN}$ are markedly reduced in size after neonatal deafening (Osofsky et al. 2001), a finding that would also strongly suggest that the $\mathrm{CN}$ projections should be reduced in size (proportionate to the $\mathrm{CN}$ ) if topographic precision were maintained after deafness.

Ryugo et al. (1997) examined the auditory nerve endings in the $\mathrm{CN}$ of congenitally deaf white cats, an animal model of early onset deafness that mimics Scheibe deformity in humans. As in the current study, their results showed well-defined, clearly recognizable endbulbs of Held in the AVCN in adult deaf white 
cats, but the endbulbs had fewer/less complex branches, and electron microscopy demonstrated reduced synaptic vesicle density and hypertrophy of the postsynaptic densities (Ryugo et al. 1997). A later study also showed modest alterations in the bouton endings on multipolar cells in the AVCN, with ultrastructural analysis demonstrating a smaller bouton size in congenitally deaf cats but no other notable differences (Redd et al. 2002). Our findings in ototoxic drug deafened cats are consistent with these previous reports suggesting that, even after deafness very early in life, the remaining auditory neurons form and maintain well-developed endings that are appropriately specialized for the specific target cell types within the $\mathrm{CN}$. Interestingly, a recent study by Ryugo et al. (2005) demonstrated reversal of the hypertrophic changes in the endbulb synapses following electrical stimulation delivered by a cochlear implant initiated at 2.5 to 5 months of age. This provides an interesting contrast to the present data. Alterations in individual synapses induced by early deafening are reversible with restoration of input from a cochlear implant, but the broader spatial distribution of the synaptic inputs from a restricted population of SG neurons (i.e., a critical band distance) induced by deafening is not reversed by electrical stimulation with an implant.

\section{Auditory nerve projections in deafened animals at 9 weeks of age}

Larsen (1984) previously reported that the $\mathrm{CN}$ in cats reaches full adult dimensions by 50 days postnatal. Our findings from high-resolution measurements of CN cross-sectional areas in digital images and calculations of volume suggest that the $\mathrm{CN}$ continues to grow over a significantly longer period (Fig. 3). Specifically, data from normal animals studied at $\sim 9$ weeks of age showed that the $\mathrm{CN}$ cross-sectional area was only $70 \%$ of full adult size. Further, data from deafened animals examined at $\sim 9$ weeks showed that the $\mathrm{CN}$ continued to grow despite a profound hearing loss early in life and was significantly larger in the older deafened animals examined at $\sim 32$ weeks. This finding raises the question of whether ipsilateral stimulation may have also activated the contralateral $\mathrm{CN}$ via commissural or descending (Shore et al. 2003) and thus elicited bilateral effects. However, we previously reported that $\mathrm{CN}$ size in a separate group of neonatally deafened animals studied at 16 weeks of age (with no electrical stimulation) was not significantly different from $\mathrm{CN}$ size in the contralateral nonstimulated $\mathrm{CN}$ of the present group of implanted animals studied at 8 months of age (Leake et al. 2006; Fig. 4C). Thus, we suggest that the $\mathrm{CN}$ growth that occurs after 9 weeks of age in these deafened animals is not dependent upon electrical stimulation; and although we cannot define the precise age when this growth is complete, our findings indicate that it continues beyond 9 weeks of age and is complete by 16 weeks of age. Given that the deafened $\mathrm{CN}$ is clearly capable of growth during this period, it is unclear why unilateral electrical stimulation did not significantly affect $\mathrm{CN}$ volume in the present study.

In addition, the finding that $\mathrm{CN}$ projections in the 9-week-old group were not significantly different in absolute thickness from the older deafened group or from normal adult cats again suggests that the $\mathrm{CN}$ projections maintain relatively constant projection widths over this age range and despite substantial differences in CN size across groups.

\section{Clinical implications for cochlear implants}

The observation that the cochleotopic order of the SG input to the central auditory system is maintained in deafened animals despite profound hearing loss at a very young age and before hearing onset may have important implications for pediatric cochlear implants. If similar principles pertain to human auditory system development, then our findings suggest that the selectivity of the primary afferent connections, which underlie the tonotopic organization of the central auditory system, is basically intact even in congenitally deaf individuals. Further, data also suggest that this organization is not significantly altered by a period of several months of unilateral electrical stimulation from a cochlear implant. This may have important implications for the application of contemporary cochlear implants in congenitally deaf individuals because these devices utilize the cochleotopic organization of the auditory nerve to appropriately encode acoustic information across multiple channels of electrical stimulation. Clinical results with implants generally tend to be poorer in congenitally deaf subjects than in individuals who have had some prior auditory experience (for reviews see Niparko 2004; Pisone and Cleary 2004). However, over time, many congenitally deaf children obtain substantial benefit from their devices, and we suggest that maintenance of the basic cochleotopic organization of the auditory nerve projections to the central auditory system must be a key component underlying that success. On the other hand, if the proportionately broader SG-to-CN projections observed in neonatally deafened animals result in poorer frequency resolution, this would suggest that there may be some inherent limitations in the efficacy of multichannel cochlear implant stimulation in congenitally deaf subjects. In particular, spatial (spectral) selectivity of electrical signals delivered on adjacent channels may be poorer in congenitally deaf cochlear implant users due to the greater overlap of central 
axons representing nearby frequencies within the CN. Given this limitation, such a cochlear implant user may be more dependent upon temporal features of the electrical stimuli delivered by the implant, and it may be advantageous to enhance the salience of such cues, e.g., even by removing some electrodes from the processor "map" to reduce channel interaction or by using moderate rates of stimulation to enhance the spectral contrasts in the signals.

\section{ACKNOWLEDGMENTS}

This research was supported by the National Institute on Deafness and Other Communication Disorders of the U.S. National Institutes of Health, Grant \#5R01-DC00160 and Contracts N01-DC-3-1006 and \#HHS-N-263-2007-00054-C. The authors gratefully acknowledge the expert technical assistance of Steve Rebscher, who designed and fabricated the custom feline cochlear implants used in this study, and Beth Dwan, who assisted in animal surgery, daily stimulation, and care of chronically implanted animals.

\section{REFERENCES}

Beitel Re, Snyder RL, Schreiner MW, Raggio MW, Leake PA. Electrical cochlear stimulation in the deaf cat: comparisons between psychophysical and central auditory neuronal thresholds. J. Neurophysiol. 83:2145-2162, 2000.

Brawer JR, Morest DK, Kane EI. The neuronal architecture of the cochlear nucleus of the cat. J. Comp. Neurol. 155:251-300, 1974.

Cang J, Renteria RC, Kaneko M, Liu X, Copenhagen DR, Stryker MP. Development of precise maps in visual cortex requires patterned spontaneous activity in the retina. Neuron 48:797-809, 2005.

CANT NB, Morest DK. The structural basis for stimulus coding in the cochlear nucleus of the cat. In: Berlin C (ed) Hearing Science: Recent Advances. San Diego, College-Hill, pp. 371-421, 1984.

Chalupa LM, SNIDER CJ. Topographic specificity in the retinocollicular projection of the developing ferret: an anterograde tracing study. J. Comp. Neurol. 392:35-47, 1998.

Cheng HJ, Nakamoto M, Bergemann AD, Flanagan JG. Complementary gradients in expression and binding of ELF-1 and Mek4 in development of the topographic retinotectal projection map. Cell 82:371-381, 1995.

Chiu C, Weliky M. Synaptic modification by vision. Science 300:1890-1891, 2003.

Clements M, Kelly JB. Directional responses by kittens to an auditory stimulus. Dev. Psychobiol. 11:505-511, 1978.

Constantine-Paton M, Cline HT, Debski E. Patterned activity, synaptic convergence and the NMDA receptor in developing visual pathways. Annu. Rev. Neurosci. 13:129-154, 1990.

Cowan WM, Fawcett JW, O'Leary DDM, Stanfield BB. Regressive events in neurogenesis. Science 225:1258-1265, 1984.

CRAMER KS. Eph proteins and the assembly of auditory circuits. Hearing Res. 206:42-51, 2005.

Cutforth T, Moring L, Mendelsohn M, Nemes A, Shah NM, Kim MM, Frisen J, Axel R. Axonal ephrin-As and odorant receptors: coordinate determination of the olfactory sensory map. Cell 114:311-322, 2003.

Dolan DF, Teas DC, Walton JP. Postnatal development of physiological responses in auditory nerve fibers. J. Acoust. Soc. Am. 78:544-554, 1985.
Easter SSJ, Purves D, Rakic P, Spitzer NC. The changing view of neural specificity. Science 230:507-511, 1985.

Ehret G, Romand R. Postnatal development of absolute auditory thresholds in kittens. J. Comp. Physiol. Psychol. 95:304-311, 1981.

Fekete DM, Rouiller EM, Liberman MC, Ryugo DK. The central projections of intracellularly labeled auditory nerve fibers in cats. J. Comp. Neurol. 229:432-450, 1984.

Feldheim DA, Kim YI, Bergemann AD, Frisen J, Barbacid M, Flanagan JG. Genetic analysis of ephrin-A2 and ephrin-A5 shows their requirement in multiple aspects of retinocollicular mapping. Neuron 25:563-574, 2000.

Feller MB, Wellis DP, Stellwagen D, Werblin DFS, Shatz CJ. Requirement for cholinergic synaptic transmission in the propagation of spontaneous retinal waves. Science 272:11821187, 1996.

Fitzakerley JL, McGee J, Walsh EJ. Characteristics of the bursting behavior found in spontaneous activity and in near-threshold discharge response of immature auditory neurons. Neurosci Abstr. 21(1):127, 1995.

FitZakerley JL, McGee J, Walsh EJ. Paradoxical relationship between frequency selectivity and threshold sensitivity during auditorynerve fiber development. J. Acoust. Soc. Am. 103(6):3464-3477, 1998.

Foss I, Flottorp G. A comparative study of the development of hearing and vision in various species commonly used in experiments. Acta Otolaryngol. 77:202-214, 1974.

FRIAUF E. Tonotopic order in the adult and developing auditory system of the rat as shown by $c$-fos immunocytochemistry. Eur. J. Neurosci. 4:798-812, 1992.

Friauf E, Kandler K. Cell birth, formation of efferent connections and establishment of tonotopic order in the rat cochlear nucleus. In: Merchan MA, Juiz JM, Godfrey DA, Mugnaini E (eds) The Mammalian Cochlear Nuclei: Organization and Function. New York, Plenum, pp. 19-28, 1993.

Friauf E, Lohmann C. Development of auditory brainstem circuitry. Activity-dependent and activity-independent processes. Cell Tissue Res. 297:187-195, 1999.

Friedlander MJ, Tootle JS. Postnatal anatomical and physiological development of the visual system. In: Coleman JR (ed) Development of Sensory Systems in Mammals. New York, Wiley, pp. 61-124, 1990.

Fritzsch B, Pauley S, Matei V, Katz DM, Xiang M, Tessarollo L. Mutant mice reveal the molecular and cellular basis for specific sensory connections to inner ear epithelia and primary nuclei of the brain. Hearing Res. 206:52-63, 2005.

Fritzsch B, Pauley S, Feng F, Matei V, Nichols DH. The evolution of the vertebrate auditory system: transformations of vestibular mechanosensory cells for sound processing is combined with newly generated central processing neurons. Intl. J. Comp. Psych. 19:1-24, 2006.

Goodman CS, Shatz CJ. Developmental mechanisms that generate precise patterns of neuronal connectivity. Cell 72/Neuron 10:77-98, 1993.

GreENwood DD. Critical bandwidth in man and some other species in relation to the traveling wave envelope. In: Moskowitz HR, Stevens JC (eds) Sensation and Measurement. Boston, Reidel, pp. 231-239, 1974.

GreENwood DD. A cochlear frequency-position function for several29 years later. J. Acoust. Soc. Am. 87:2593-2605, 1990.

Guillery RW, STELzNer DJ. The differential effects of unilateral lid closure upon the monocular and binocular segments of the dorsal lateral geniculate nucleus in the cat. J. Comp. Neurol. 139:413-421, 1970.

Hansen MJ, Dallal Ge, Flanagan JG. Retinal axon response to ephrins shows a graded, concentration dependent transition from growth promotion to inhibition. Neuron 42:717-730, 2004. 
Hartmann R, KLinke R. Response characteristics of nerve fibers to patterned electrical stimulation. In: Miller JM, Spelman FA (eds) Cochlear Implants: Models of the Electrically Stimulated Ear. New York, Springer, pp. 135-160, 1989.

Hartmann R, Topp G, KLinke R. Single fiber recordings from the cat auditory nerve with electrical stimulation of the cochlea at different stimulation places. Ann. Otol. Rhinol. Laryngol. 96 (Suppl. 128):30-31, 1987.

Jackson H, Parks TN. Functional synapse elimination in the developing avian cochlear nucleus with simultaneous reduction in cochlear nerve axon branching. J. Neurosci. 2:1736-1743, 1982.

Jones T, Leake PA, Snyder RL, Bonham B, Stakhovskaya O. Spontaneous discharge patterns in cochlear spiral ganglion cells prior to the onset of hearing in cats. J. Neurophysiol. 98(4):18981908, 2007.

Keithley EM, Cronin-Schreiber R. Frequency map of the spiral ganglion in the cat. J. Acoust. Soc. Am. 81:1036-1042, 1987.

Kiang NYS, Watanabe T, Thomas EC, Clark LF. Discharge patterns of single fibers in the cat's auditory nerve. Cambridge, MA, MIT, 1965.

Kitzes L. Anatomical and physiological changes in the brainstem induced by neonatal ablation of the cochlea. In: Salvi RJ, Henderson D (eds) Auditory System Plasticity and Regeneration. New York, Thieme Medical, pp. 256-274, 1996.

Kitzes LM, Kageyama GH, Semple MN, Kil J. Development of ectopic projection s from the ventral cochlear nucleus to the superior olivary complex induced by neonatal ablation of the contralateral cochlea. J. Comp. Neurol. 353(3):341-363, 1995.

LARSEN SA. Postnatal maturation of the cat cochlear nuclear complex. Acta Otolaryngol. Suppl. 417:1-43, 1984.

LeAKe PA, Rebscher SJ. Anatomical considerations and long-term effects of electrical stimulation. In: Zeng FG, Popper AN, Fay RR (eds) Auditory Prostheses. Springer Handbook of Auditory Research. New York, NY, Springer, pp. 101-148, 2004.

LEAKE PA, SNYDER RL. Topographic organization of the central projections of the spiral ganglion in cats. J. Comp. Neurol. 281:612-629, 1989

Leake PA, Kuntz AL, Moore CM, Chambers PL. Cochlear pathology induced by aminoglycoside ototoxicity during postnatal maturation in cats. Hearing Res. 113:117-132, 1997.

LEAKE PA, HRADEK GT, SNYDER RL. Chronic electrical stimulation by a cochlear implant promotes survival of spiral ganglion neurons after neonatal deafness. J. Comp. Neurol. 412:543-562, 1999.

Leake PA, SNyder RL, Rebscher SJ, Moore CM, Vollmer M. Plasticity in central representations in the inferior colliculus induced by chronic single-vs. two-channel electrical stimulation by a cochlear implant after neonatal deafness. Hearing Res. 147:221-24, 2000.

Leake PA, Snyder RL, Hradek G. Postnatal refinement of auditory nerve projections to the cochlear nucleus in cats. J. Comp. Neurol. 448(1):6-27, 2002.

Leake PA, Hradek GT, Chair L, Snyder RL. Neonatal deafness results in degraded topographic specificity of auditory nerve projections to the cochlear nucleus in cats. J. Comp. Neurol. 497:1331, 2006.

Leake PA, Hradek GT, Vollmer M, Rebscher SJ. Neurotrophic effects of GM1 ganglioside and electrical stimulation on cochlear spiral ganglion neurons in cats deafened as neonates. J Comp Neurol. 501:837-853, 2007.

LEVAY S, STRYKer MP, ShATZ CJ. Ocular dominance columns and their development in layer IV of the cat's visual cortex: a quantitative study. J. Comp. Neurol. 179:1-51, 1978.

Liberman MC. The cochlear frequency map for the cat: labeling auditory nerve fibers of known characteristic frequency. J. Acoust. Soc. Am. 72:1441-1449, 1982.

Limb CJ, Ryugo DK. Development of primary axosomatic endings in the anteroventral cochlear nucleus of mice. J. Assoc. Res. Otolaryngol 1(2):103-119, 2000.
Maffei L, Galli-Resta L. Correlation in the discharges of neighboring rat retinal ganglion cells during prenatal life. Proc. Natl. Acad. Sci. U. S. A. 87:2861-2864, 1990.

McLaughlin T, O'Leary DDM. Molecular gradients and development of retinotopic maps. Annu. Rev. Neurosci. 28:327-355, 2005.

McLaughlin T, Hindges R, Yates PA, O’Leary DD. Bifunctional action of ephrin-B1 as a repellent and attractant to control bidirectional branch extension in dorsal-ventral retinotopic mapping. Development 130:2407-2418, 2003a.

Mclaughlin T, Torborg Cl, Feller MB, O’Leary DD. Retinotopic map refinement requires spontaneous retinal waves during a brief critical period of development. Neuron 40:1147-1160, 2003b.

Molea D, Rubel EW. Timing and topography of nucleus magnocellularis innervation by the cochlear ganglion. J. Comp. Neurol. 466:577-591, 2003.

Moore DR, Kitzes LM. Projections from the cochlear nucleus to the inferior colliculus in normal and neonatally cochlea-ablated gerbils. J. Comp. Neurol. 240:180-195, 1985.

MoORe DR, KowalchuK NE. Auditory brainstem of the ferret: effects of unilateral cochlear lesions in cochlear nucleus volume and projections to the inferior colliculus. J. Comp. Neurol. 272:503$515,1988$.

Niparko J. Cohlear implants: Clinical applications. In: Zeng FG, Popper AN, Fay RR (eds) Auditory Prostheses. Springer Handbook of Auditory Research. New York, NY, Springer, pp. 53-100, 2004

O'Leary DD, McLaughlin T. Mechanisms of retinotopic map development: Ephs, ephrins, and spontaneous correlated retinal activity. Prog Brain Res 147:43-65, 2005.

O'LeARY DDM, WiLKINSON DG. Eph receptors and ephrins in neural development. Curr. Opin. Neurobiol. 9:65-73, 1999.

O'Leary EE, Yates PA, McLaughlin T. Molecular development of sensory maps: representing sights and smells in the brain. Cell 96:255-269, 1999.

Osen KK. Cytoarchitecture of the cochlear nuclei in the cat. J. Comp. Neurol. 136:453-484, 1969.

OsEN KK. Course and termination of the primary afferents in the cochlear nuclei of the cat: an experimental anatomical study. Arch. Ital. Biol. 108:21-51, 1970.

Osofsky MR, Moore CM, Leake PA. Does exogenous GM1 ganglioside enhance the effects of electrical stimulation in ameliorating degeneration after neonatal deafness? Hearing Res. 159:23-35, 2001.

PARKINs CW. Temporal response patterns of auditory nerve fibers to electrical stimulation in deafened squirrel monkeys. Hearing Res. 41:137-168, 1989.

Person Al, Cerretti dP, Pasquale EB, Rubel EW, Cramer KS. Tonotopic gradients of Eph family proteins in the chick nucleus laminaris during synaptogenesis. J. Neurobiol. 60:28-39, 2004.

PisOne DB, CleARY M. Learning, memory and cognitive processes in deaf children following cochlear implantation. In: Zeng FG, Popper AN, Fay RR (eds) Auditory Prostheses. Springer Handbook of Auditory Research. New York, NY, Springer, pp. 377-426, 2004.

Prakash N, Vanderhaeghen P, Cohen-Cory S, Frisen J, Flanagan JG, Frostig RD. Malformation of the functional organization of somatosensory cortex in adult ephrin-A5 knock-out mice revealed by in vivo functional imaging. J. Neurosci. 20:5841-5847, 2000.

Pujol R. Development of tone-burst responses along the auditory pathway in the cat. Acta Otolaryngol. 74:383-391, 1972.

RASBAND WS. Image J, U. S. National Institutes of Health, Bethesda, Maryland, USA, http://rsb.info.nih.gov/ij/, 2006.

Redd EE, Cahill HB, Pongstaporn T, Ryugo D. The effects of congenital deafness on auditory nerve synapses: type I and type II multipolar cells in the anteroventral cochlear nucleus of cats. JARO 3:403-417, 2002. 
Romand R. Functional properties of auditory-nerve fibers during postnatal development in the kitten. Exp. Brain Res. 56:395402, 1984.

Rouiller EM, Cronin-Schreiber R, Fekete DM, Ryugo DK. The central projections of intracellularly labeled auditory nerve fibers in cats: an analysis of terminal morphology. J. Comp. Neurol. 249:261-278, 1986

Rubel EW, Cramer KS. Choosing axonal real estate: location, location, location. J. Comp. Neurol. 448:1-5, 2002.

Rubel EW, Fritzsch B. Auditory system development: primary auditory neurons and their targets. Ann. Rev. Neurosci. 25:51101, 2002.

Ruthazer ES, Cuine HT. Insights into activity-dependent map formation from the retinotectal system: a middle-of-the-brain perspective. J. Neurobiol. 59:134-146, 2004.

Ryan AF, Woolf NK. Development of tonotopic representation in the Mongolian gerbil: a 2-deoxyglucose study. Dev. Brain Res. 41:61-70, 1988.

Ryugo DK, FeKETE DM. Morphology of primary axosomatic endings in the anteroventral cochlear nucleus of the cat: a study of the endbulbs of Held. J. Comp. Neurol. 210:239-257, 1982.

Ryugo DK, Ponstaporn T, Huchton DM, Niparko JK. Ultrastructural analysis of primary endings in deaf white cats: morphologic alteration in endbulbs of Held. J. Comp. Neurol. 385:230-244, 1997.

Ryugo DK, Kretzmer EA, Niparko JK. Restoration of auditory nerve synapses in cats by cochlear implants. Science 310:1490-1492, 2005.

Sachs GM, Jacobson M, Caviness VS. Postnatal changes in arborization patterns of murine retinocollicular axons. J. Comp. Neurol. 246:395-408, 1986.

Sanes DH, Merickel M, Rubel EW. Evidence for an alteration of the tonotopic map in the gerbil cochlea during development. J. Comp. Neurol. 279:436-444, 1989.

Schweitzer L, Cecil T. Morphology of HRP-labeled cochlear nerve axons in the dorsal cochlear nucleus of the developing hamster. Hearing Res. 60:34-44, 1992.

SHATz CJ. Impulse activity and the patterning of connections during CNS development. Neuron 5:745-756, 1990.

Shatz CJ. Emergence of order in visual system development. Proc. Natl. Acad. Sci. U. S. A. 93:602-608, 1996.

SHEPHERD RK, JAVEL E. Electrical stimulation of the auditory nerve. I. Correlation of physiological responses with cochlear status. Hearing Res. 108:112-144, 1997.

Shore SE, Sumner CJ, Bledsoe SC, Lu J. Effects of contralateral sound stimulation on unit activity of ventral cochlear nucleus neurons. Exp. Brain Res. 153(4):427-435, 2003.

SiddiQui SA, Cramer KS. Differential expression of Eph receptors and Ephrins in the cochlear ganglion and eighth cranial nerve of the chick embryo. J. Comp. Neurol. 482:309-319, 2005.

SNYDER RL, LeAKe PA. Topography of spiral ganglion projection to the cochlear nucleus during postnatal development in cats. J. Comp. Neurol. 384:293-311, 1997.

Shyder RL, Rebscher SJ, Cao K, Leake PA. Effects of chronic intracochlear electrical stimulation in the neonatally deafened cat. I: expansion of central spatial representation. Hear Res. 50:7-33, 1990.

SNyder RL, Leake PA, Hradek GT. Quantitative analysis of spiral ganglion projections to the cat cochlear nucleus. J. Comp. Neurol. 379:133-149, 1997.
Snyder RL, Snyder RL, Vollmer M, Moore CM, Rebscher SJ, Leake PA. Responses of inferior colliculus neurons to amplitude modulated intracochlear electrical pulses in deaf cats. J. Neurophysiol. 84:166-183, 2000.

SRetavan DW, Shatz CJ. Prenatal development of retinal ganglion cell axons: segregation into eye-specific layers within the cat's lateral geniculate nucleus. J. Neurosci. 6:234-251, 1986.

Sretavan D, Shatz C. Axon trajectories and pattern of terminal arborization during prenatal development of the cat's retinogeniculate pathway. J. Comp. Neurol. 255:356-400, 1987.

Sur M, Weller RE, Sherman SM. Development of X- and Y-cells retinogeniculate terminations in kittens. Nature Lond. 310:246249, 1984

TAO HW, Poo M-M. Activity-dependent matching of excitatory and inhibitory inputs during refinement of visual receptive fields. Neuron 45:829-836, 2005.

Tatton WG, Chalmers-Redman RMe, Pong A, Rideout HJ, Tatton NA. Neuronal death and deprenyl in Parkinson's disease: a conceptual journey from MAO-B to glyceraldehyde-3-phosphate dehydrogenase. GreyCell Pharm. Res. 914:1-13, 1999.

Tolbert LB, Morest DK. The neuronal architecture of the anteroventral cochlear nucleus of the cat in the region of the cochlear nerve root: electron microscopy. Neurosci 7:3053-3067, 1982.

Vollmer M, Leake PA, Beitel R, Rebscher SJ, Snyder RL. Degradation in temporal resolution in the auditory midbrain after prolonged deafness is reversed by electrical stimulation of the cochlea. J. Neurophysiol. 93:3339-3355, 2005.

Vollmer M, Snyder RL, Leake PA, Moore CM, Rebscher SJ. Temporal properties of chronic intracochlear electrical stimulation determine temporal resolution of neurons in the cat inferior colliculus. J. Neurophysiol. 82:2883-2902, 1999.

Walsh EJ, McGee J. The development of function in the auditory periphery of cats. In: Altschuler RA, Bobbin RP, Hoffman DW (eds) Neurobiology of Hearing: The Cochlea. New York, Raven, pp. 247-269, 1986.

Walsh EJ, McGeE J. Postnatal development of auditory nerve and cochlear nucleus neuronal responses in kittens. Hearing Res. 28:97-116, 1987.

WAlsh EJ, McGeE J. Frequency selectivity in the auditory periphery: similarities between damaged and developing ears. Am. J. Otolaryngol. 11:23-32, 1990.

Walsh EJ, Romand R. Functional development of the cochlea and cochlear nerve. In: Romand R (ed) Development of Auditory and Vestibular Systems 2. Amsterdam, Elsevier, pp. 161-219, 1992.

Walsh EJ, McGee J, McFadden SL, Liberman MC. Long-term effects of sectioning the olivocochlear bundle in neonatal cats. J. Neurosci. 18(10):3859-3869, 1998.

WEBSTER WR, Martin RL. The development of frequency representation in the inferior colliculus of the kitten. Hearing Res. 55:70-80, 1991.

Xiang M, Maklad A, Privola U, Fritzsch B. Brn3c null mutant mice show long-term, incomplete retention of some afferent inner ear innervation. BMC Neurosci. 4:2, 2003, DOI 10.1186/1471-2202-4-2.

Young SR, Rubel EW. Embryogenesis of arborization pattern and topography in nucleus laminaris of the chicken brain stem. J. Comp. Neurol. 254:425-459, 1986.

Zhou Q, Taо HW, Poo MM. Reversal and stabilization of synaptic modifications in a developing visual system. Science 300:19531957, 2003. 